\title{
Resíduos de praguicidas em amostras de ovo comercializadas na cidade de São Paulo
}

Tese apresentada ao Programa de Pós-Graduação em Patologia Experimental e Comparada da Faculdade de Medicina Veterinária e Zootecnia da Universidade de São Paulo para obtenção do título de Doutor em Ciências.

Área de concentração: Patologia Experimental e Comparada

Orientadora: Prof. Dra. Helenice de Souza Spinosa 
Autorizo a reprodução parcial ou total desta obra, para fins acadêmicos, desde que citada a fonte.

DADOS INTERNACIONAIS DE CATALOGAÇÃO-NA-PUBLICAÇÃO

(Biblioteca Virginie Buff D’Ápice da Faculdade de Medicina Veterinária e Zootecnia da Universidade de São Paulo)

Ciscato, Cláudia Helena Pastor

Resíduos de praguicidas em amostras de ovo comercializadas na cidade de São Paulo / Cláudia Helena Pastor Ciscato. - São

Paulo : C. H. P. Ciscato, 2008.

$105 \mathrm{f}$ : : il.

Tese (doutorado) - Universidade de São Paulo. Faculdade de Medicina Veterinária e Zootecnia. Departamento de Patologia, 2008.

Programa de Pós-Graduação: Patologia Experimental e Comparada.

Área de concentração: Patologia Experimental e Comparada.

Orientador: Profa. Dra. Helenice de Souza Spinosa.

1. Praguicidas. 2. Resíduos. 3. Ovo. 4. Multirresíduos. 5. Avaliação de risco. I. Título. 


\section{FOLHA DE APROVAÇÃO}

Cláudia Helena Pastor Ciscato

Resíduos de praguicidas em amostras de ovo

comercializadas na cidade de São Paulo

Tese apresentada à Faculdade de Medicina Veterinária e Zootecnia da Universidade de São Paulo para obtenção do título de Doutor.

Área de concentração: Patologia Experimental e Comparada

Aprovado em:

\section{Banca Examinadora}

Prof. Dr.

Instituição:

Assinatura:

Prof. Dr.

Instituição:

Assinatura:

Prof. Dr.

Instituição:

Assinatura:

Prof. Dr.

Instituição:

Assinatura:

Prof. Dr.

Instituição:

Assinatura: 
As invenções são sobretudo os resultados de um trabalho teimoso. (Santos Dumont) 
Aos meus pais. 
A meu irmão e meus sobrinhos. 


\section{AGRADECIMENTOS}

- A Prof. Dra. Helenice de Souza Spinosa pela orientação e colaboração;

- Ao Dr. Amir Bertoni Gebara pela amizade e estímulo;

- Ao Prof. Dr. João Palermo Neto pela oportunidade;

- A Dra. Marilene da Silva Ferreira pela amizade e apoio;

- Aos colegas do Laboratório de Resíduos de Pesticidas do Instituto Biológico por toda a ajuda durante o decorrer do trabalho;

- Aos meus amigos pelo carinho e lealdade. 
RESUMO 


\section{RESUMO}

CISCATO, C. H. P. Resíduos de praguicidas em amostras de ovo comercializado na cidade de São Paulo. 2008. 105 f. Tese (Doutorado em Ciências) - Faculdade de Medicina Veterinária e Zootecnia, Universidade de São Paulo, São Paulo, 2008.

O uso de praguicidas na agricultura e pecuária pode acarretar sérios problemas à saúde dos seres humanos e dos animais. O controle da presença destas substâncias nos alimentos e no meio ambiente são um instrumento importante para minimizar o risco da exposição a estas substâncias. No Brasil, as informações sobre resíduos de praguicidas são insuficientes, especialmente quando se trata de produtos de origem animal. Um importante nutriente na dieta dos seres humanos é o ovo, principalmente na dieta infantil. De acordo com a FAO o Brasil ocupa o $7^{\circ}$ lugar na produção de ovos com 1,72 milhões de dúzias por ano e um consumo per capita de 1,7 kg/ano (IBGE, 2003). Embora o consumo de ovos no Brasil seja um aspecto importante a maior parte da produção é exportada para outros países, principalmente, Arábia Saudita, China, Japão e Holanda. Este estudo foi desenvolvido no período de Janeiro de 2004 a Dezembro de 2006, um total de 150 amostras de ovos foram coletadas no mercado e avaliadas para a presença de resíduos de praguicidas organoclorados, organofosforados e piretróides. O método utilizado nas analises para determinar os resíduos de praguicidas nas amostras foi o DFG S19. Este método consiste em extração com solvente orgânico, etapa de partição com diclorometano e purificação com o emprego de cromatografia de permeação a gel e mini-coluna de sílica gel. Para a identificação e quantificação foi utilizada a metodologia analítica de cromatografia gasosa com detectores de captura de elétrons, nitrogênio/fósforo e fotométrico de chama. Os estudos de recuperação estiveram dentro da faixa de 70 a $120 \%$. Os resultados das analises mostraram que o herbicida alacloro foi detectado em $0,7 \%$ das amostras analisadas e a sua contribuição para a ingestão diária crônica foi avaliada. Este praguicida não possui LMR em ovo, assim como o parâmetro de ingestão diária aceitável não foi estabelecido, porém a presença em ovo pode ser atribuída a alimentação dos animais e este praguicida devido a presença de cloro na molécula pode contribuir para o risco crônico à saúde humana. Embora apenas uma amostra tenha tido um 
resultado positivo, o controle dos alimentos destinados a população são um importante fator a ser controlado para garantir a saúde da população.

Palavras-chave: Praguicidas. Resíduos. Ovo. Ingestão diária aceitável. Risco a saúde. 
ABSTRACT 


\begin{abstract}
CISCATO, C. H. P. Pesticide residue in egg samples commercialized in Sao
\end{abstract} Paulo City. 2008. 105 f. Thesis (Doctorate) - Faculdade de Medicina Veterinária e Zootecnia, Universidade de São Paulo, São Paulo, 2008.

The use of pesticides in agriculture and livestock can cause serious problem for human beings and animal health. The control of these substances in food and in the environment is an important instrument to minimize these risks. In Brazil information about pesticide residues on food are insufficient, especially for animal products. An important nutrient supply on human diet is the egg, it provides several nutrients especially for children. According to FAO Brazil is the $7^{\text {th }}$ in world ranking production and produces 1.72million dozen/year and the consumption is around $1.7 \mathrm{~kg} / \mathrm{year}$ (IBGE, 2003). Despite of the Brazilian scene the consumption per capita almost of egg production is exported to other countries and the main countries are Saudi Arabia, China, Japan and Netherlands. The study was developed from January 2004 to 2006, 150 egg samples were collected from the national market and evaluated for pesticide residues of organochlorine, organophosphorus and pyrethroids pesticides. A multiresidue method were employed to determinate the pesticide in samples. The method uses an organic solvent extraction, a partition with dichloromethane and purification step by gel permeation chromatography (GPC) and silica gel column. For identification and quantification it was used gas chromatography techinique with ECD, NPD and FPD detectors. The recoveries for the method were within 70 to $120 \%$. The results of the analysis showed that the herbicide alachlor were detected in $0.7 \%$ of the samples and the chronic dietary intake was evaluated. The pesticide does not have a proper use in egg, no MRL established and no ADI parameter. The presence could be attributed to feed contamination and the contribution to health risk could be detached once it has a chlorine molecule which could contribute to chronic diseases. Although only one sample was positive to pesticide residues this result is important to food quality control and consumer health. It helps to emphasize the risk studies on pesticide residues on animal and vegetable food.

Keywords: Pesticides. Residues. Egg. Chronic dietary intake. Health risk. 
SUMÁRIO 


\section{SUMÁRIO}

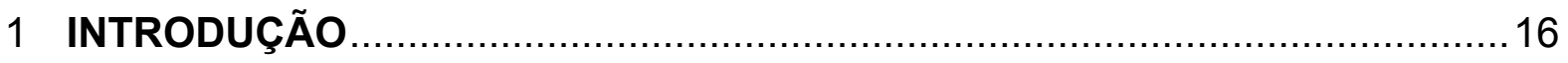

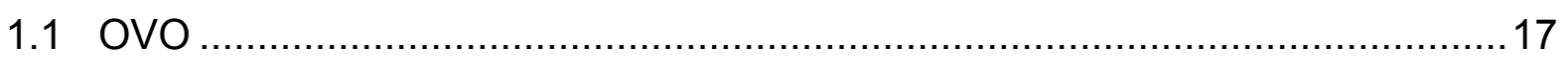

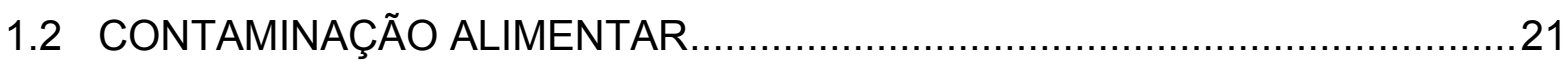

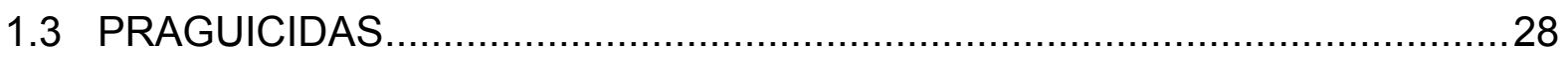

2 OBJETIVO

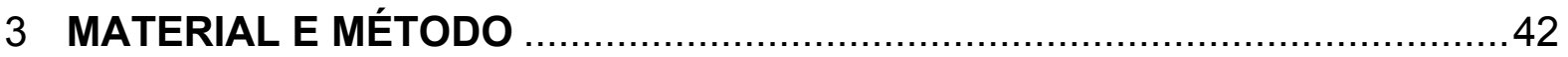

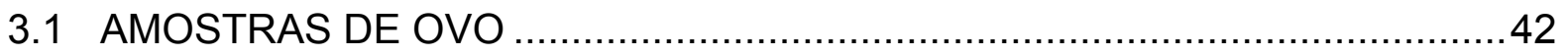

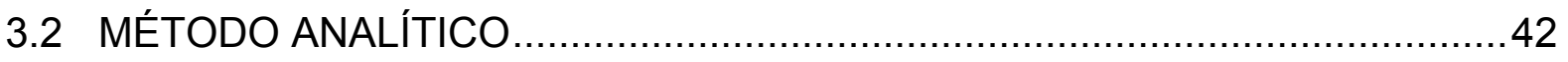

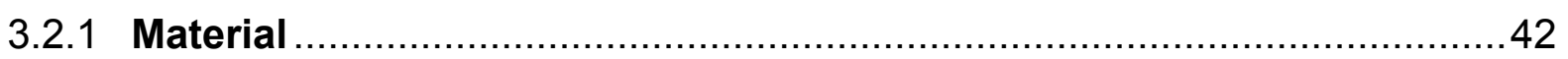

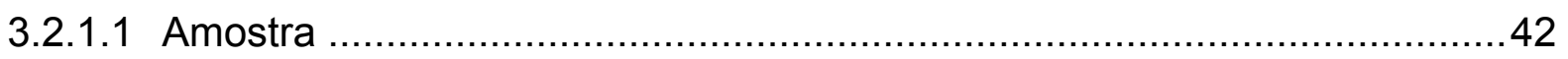

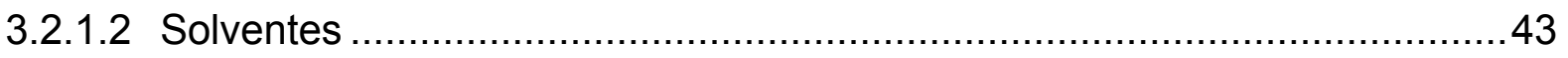

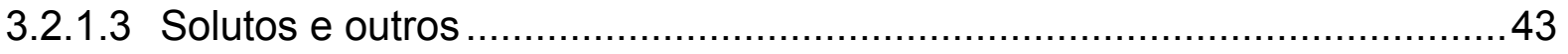

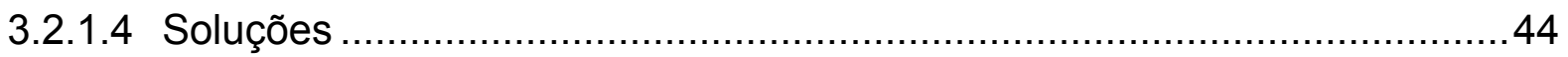

3.1.1.1.1 Solução para cromatografia de permeação a gel (GPC)......................... 44

3.1.1.1.2 Eluentes da coluna de sílica..............................................................4 44

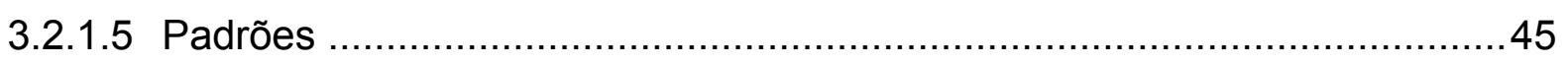

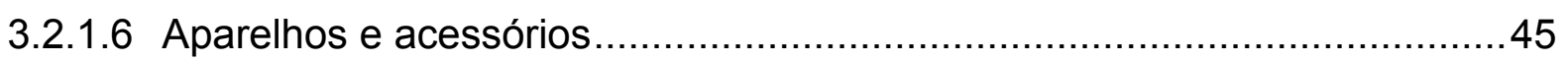

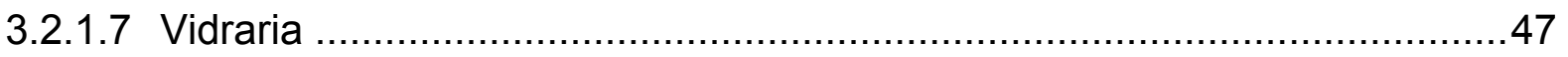

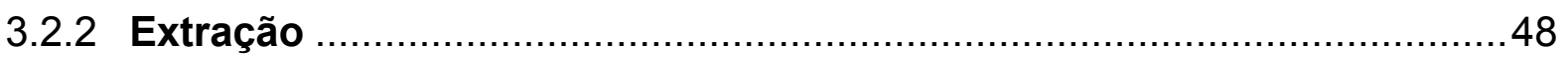

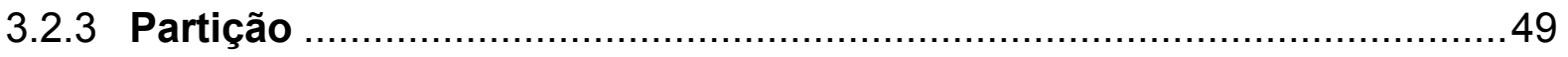

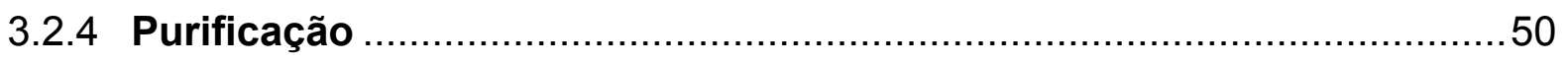

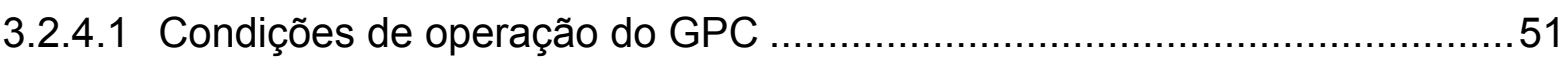

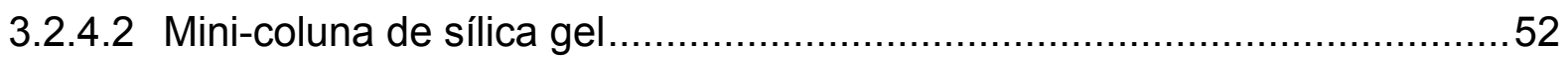

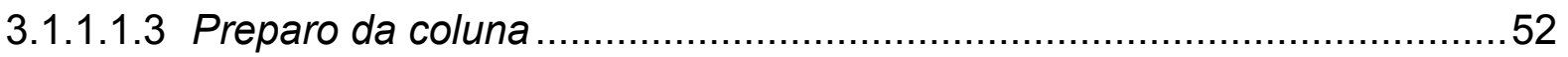

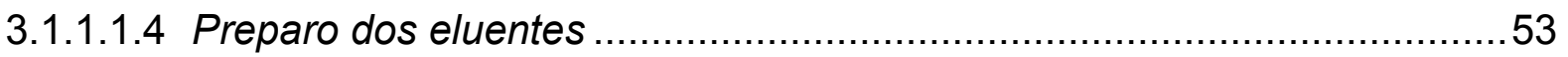

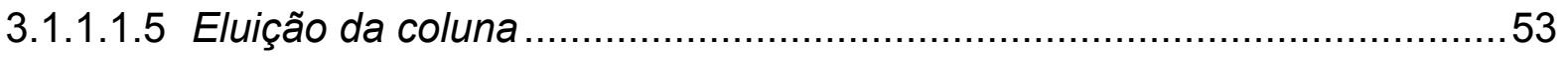

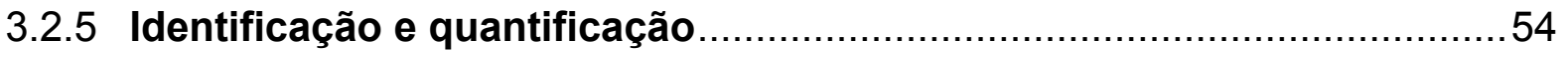

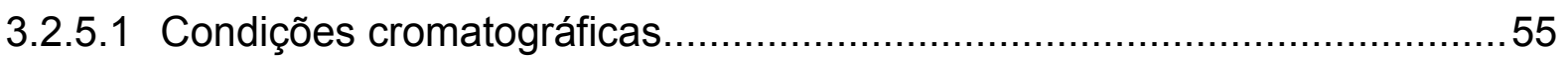

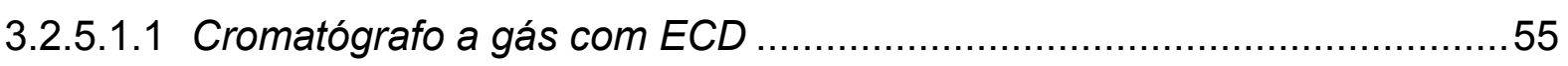

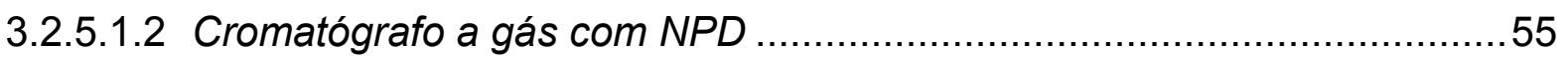

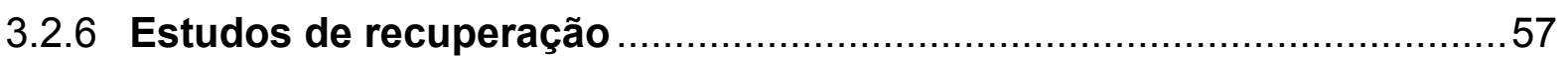




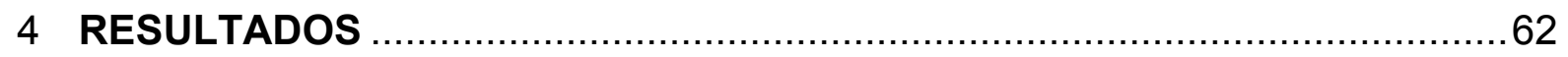

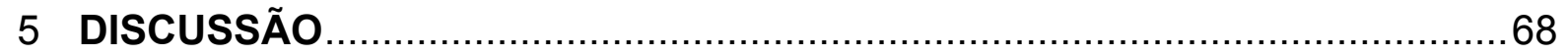

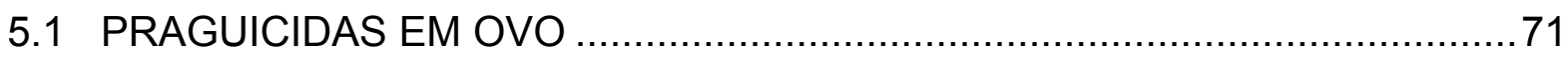

5.2 PRAGUICIDAS, MEIO AMBIENTE E OUTRAS AVES ...............................78

5.3 RISCO ASSOCIADO À PRESENÇA DE PRAGUICIDAS NOS ALIMENTOS.. 88

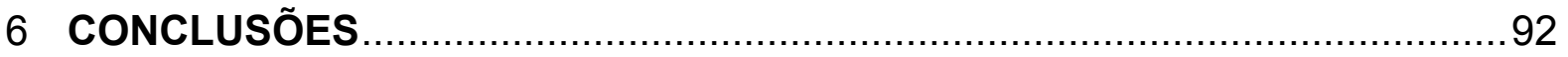

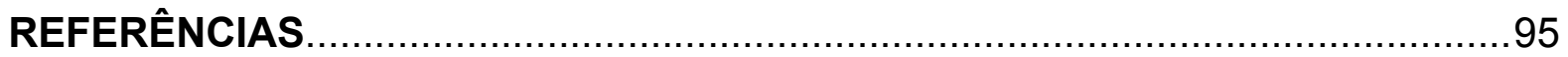


INTRODUÇÃO 


\section{INTRODUÇÃO}

O "alimento" devido a sua importância para a manutenção das populações de seres vivos deve estar disponível e em quantidade suficiente, possibilitando desta forma o fornecimento de carboidratos, de proteínas, de sais minerais e de vitaminas importantes para o desenvolvimento.

No meio ambiente cada ser vivo possui uma forma diferente de conseguir os nutrientes adequados à manutenção da vida. Os seres humanos, graças à capacidade de adaptação e criação, passaram por transformações na forma de obtenção e nos hábitos alimentares. Estas modificações incluem técnicas de produção de alimentos, processos de urbanização e, mais recentemente, a globalização, também chamada de transição nutricional

As mudanças na dieta alimentar levaram a um aumento na expectativa de vida da população. Com todas as modificações decorrentes do desenvolvimento e do crescimento da população, ficou valorizado o conceito de que há necessidade de se produzir mais comida e que a distribuição das mesmas seja feita para as diferentes partes do mundo. Desta forma, os alimentos passaram para a categoria de industrializados e os consumidores viram crescer as oportunidades de conhecer produtos provenientes de regiões distantes, ampliando as opções de escolha.

Os alimentos produzidos normalmente para a manutenção da população são, além da água, os de origem vegetal e os de origem animal. Dentre os alimentos de origem animal que têm importância dentro da produção de alimentos, destaca-se o ovo. Este produto, formado pelas aves que após a fecundação origina um outro ser vivo, possui, quantidade de nutrientes suficiente, para o desenvolvimento do embrião e também pode ser uma fonte nutritiva para outros animais, inclusive o homem. 
$\mathrm{Na}$ parte nutritiva dos ovos, formada pela clara e pela gema é possível encontrar água, sais minerais, carboidratos proteínas e gorduras, sendo que $12,5 \%$ correspondem às proteínas e $10,8 \%$ às gorduras. Devido a estas características nutricionais o ovo é considerado uma excelente fonte alimentar, contribuindo para os seres humanos com $4 \%$ da quantidade de energia e nutrientes necessários para a manutenção da vida (EGGS; NUTRITION, 2004).

\subsection{OVO}

O ovo pode ser definido como um produto de biotransformação onde as aves a partir de recursos alimentares de baixo valor nutritivo produzem um produto de elevada qualidade nutricional (BENEZ, 1997).

Uma ave poedeira pode botar até 320 ovos/ano, sendo que, por ano a ave é capaz de produzir $2.300 \mathrm{~g}$ de proteínas ricas em aminoácidos essenciais e $2.000 \mathrm{~g}$ de gorduras ricas em fosfolipídios importantes, além de vitaminas (BENEZ, 1997).

Os diferentes nutrientes encontrados nos ovos e que contribuem na dieta alimentar dos seres humanos estão apresentados na Tabela 1. 
Tabela 1 - Constituintes do ovo e contribuição na dieta alimentar

\begin{tabular}{lccc}
\hline Constituinte & $\begin{array}{c}\text { Quantidade } \\
\text { no ovo }\end{array}$ & \multicolumn{2}{c}{ \% de nutriente na dieta alimentar } \\
\cline { 3 - 4 } & & Homem & Mulher \\
\hline Peso & $51,6 \mathrm{~g}$ & - & - \\
Água & $38,8 \mathrm{~g}$ & - & - \\
Energia & $76 \mathrm{kcal}$ & 3 & 4 \\
Proteína & $6,5 \mathrm{~g}$ & 12 & 14 \\
Carboidrato & traços & - & - \\
Gordura & $5,6 \mathrm{~g}$ & - & - \\
Sódio & $72 \mathrm{mg}$ & 4,5 & 4,5 \\
Potássio & $67 \mathrm{mg}$ & 3 & 3 \\
Cálcio & $29 \mathrm{mg}$ & 4 & 4 \\
Fósforo & $103 \mathrm{mg}$ & 19 & 19 \\
Magnésio & $6,2 \mathrm{mg}$ & 2 & 2 \\
Ferro & $1 \mathrm{mg}$ & 7 & 11 \\
Zinco & $0,7 \mathrm{mg}$ & 10 & 7 \\
Cobre & $0,04 \mathrm{mg}$ & 3 & 3 \\
lodo & $27 \mathrm{mg}$ & 19 & 19 \\
Cloro & $83 \mathrm{mg}$ & 3 & 3 \\
Enxofre & $93 \mathrm{mg}$ & - & - \\
Selênio & $6 \mu \mathrm{g}$ & 10 & 8 \\
\hline
\end{tabular}

Fonte: (EGGS; NUTRITION, 2004).

Este alimento além de contribuir na dieta alimentar, por ser uma importante fonte de nutrição, também pode fornecer outras substâncias que quando administradas às aves podem fazer parte dos ovos (BENEZ, 1997). Durante a produção de ovos, aditivos alimentares, vitaminas, sais minerais, medicamentos e outras substâncias são administrados às aves. No Brasil, sabe-se que pigmentos naturais como o "SunRed" podem ser utilizados por granjeiros com a intenção de alterar a cor da gema dos ovos. Este produto a base de páprica favorece a 
coloração amarelada ou alaranjada da gema dos ovos, adequando o mesmo aos critérios de qualidade exigidos para a exportação deste alimento e para a comercialização em nível nacional (MONTEIRO, 2005).

O fato de várias substâncias químicas poderem ser administradas as aves mostra a importância de se avaliar o que é fornecido como elementos nutricionais ou o que é utilizado como tratamento para manutenção da saúde dos animais. Sabe-se que os praguicidas são utilizados na agropecuária no combate a insetos, ácaros e doenças dos animais. Estas substâncias químicas podem contaminar indiretamente o alimento produzido por estes indivíduos, expondo assim os seres humanos aos diversos tipos de contaminantes.

No Brasil existem alguns padrões nas características dos ovos para o consumo humano que levam em consideração a cor, a textura da casca, o tamanho do ovo, além de condições de armazenamento e presença de aditivos. Assim, o Decreto $n^{\circ} 56.585$ de 20/07/1965 referente a, "Nova especificação para a classificação e fiscalização do ovo", em seu artigo $1^{\circ}$ explicita: "pela designação de ovo, entende-se o ovo de galinha, sendo os demais, acompanhados da indicação da espécie de que procedem". Os ovos são classificados em grupo de acordo com a coloração da casca e do peso. Quanto à cor, o ovo é classificado como branco e de cor; quanto à classe, o ovo é classificado em $\mathrm{A}, \mathrm{B}$ e $\mathrm{C}$ que diferem quanto à textura da casca, tamanho da câmara de ar e qualidade da clara e da gema. Ainda dentro da classificação dos ovos, estes são classificados em extra, 60 g; grande, 55 g; médio, $50 \mathrm{~g}$ e pequeno, $45 \mathrm{~g}$. Os ovos devem ser acondicionados em embalagens padrões com as respectivas classificações indicadas na embalagem.

Os ovos também recebem uma classificação relacionada à identidade e qualidade do ovo integral que considera o tipo de processamento que tenha sido 
aplicado, como: resfriado, congelado, pasteurizado/resfriado, pasteurizado/congelado e desidratado - Resolução n005 de 05/07/1991 do Ministério da Agricultura, Pecuária e Abastecimento (MAPA). A composição e fatores essenciais à qualidade deste alimento também se encontram citados na referida Resolução. Esta resolução ainda trata de aditivos intencionais e coadjuvantes de tecnologia de fabricação, porém é importante salientar que as normas não consideram os estudos de controle de qualidade para a determinação de contaminantes, tais como, os praguicidas.

No Brasil a produção é de 2.515.773 dúzias de ovos/ano, o que corresponde a 183.494.626 galinhas poedeiras (BRASIL, 2004). A maior parte desta produção é exportada para países como a Arábia Saudita, China, Japão e Holanda (256,0; 131,7; 100,6 e 70,4 mil dúzias de ovos, respectivamente - BRASIL, 2004), colocando o Brasil em $7^{\circ}$ lugar na produção mundial de ovos (FAO, 2007). O ovo está no mercado brasileiro como um dos 100 principais produtos de comercialização interna (IBGE, 2008) e o consumo per capita é de 94 ovos/ano (BERTECHINI, 2004), sendo que na cidade de São Paulo ele é distribuído por mais de 1.017 estabelecimentos comerciais, desde grandes redes de supermercados até pequenos comércios e distribuição caseira.

No estudo feito pelo IBGE, em 2004 pode-se identificar a aquisição de ovos por região do país e consumo per capita. A amostragem foi feita em domicílios permanentes/particulares, sendo identificados como unidade básica de consumo, e revelou-se que a aquisição per capita de ovos de galinha por região é: região Sul 5,521 kg; região Sudeste 0,098 kg; região Centro-Oeste 2,182 kg; região Nordeste 1,848 kg e região Norte 2,488 kg. Neste estudo constatou-se, ainda, que a aquisição per capita está relacionada a faixa de renda. Apesar de ser um alimento disponível, 
de alto poder nutritivo e barato para toda a população, observou-se que os indivíduos de baixa renda consomem menos ovos (IBGE, 2004). Santos Filho e Shlindwein (2007) comentaram que os dados do POF (Pesquisa de Orçamentos Familiares) do IBGE não consideram o consumo de ovos fora do domicílio, aqueles ingeridos na forma de bolos, doces, biscoitos, burguers etc., aqueles consumidos nos períodos festivos (Páscoa, Festas Juninas, Natal etc.), além de não considerar a distribuição populacional das áreas rurais e urbanas.

O panorama do consumo de ovo no Brasil mostra que este alimento é importante na dieta alimentar do brasileiro, assim como é um importante produto de exportação para outros países onde desempenham papel fundamental na dieta, como, por exemplo, a China. Neste contexto, a contaminação deste alimento, principalmente por praguicidas, é um aspecto importante a ser discutido.

\subsection{CONTAMINAÇÃO ALIMENTAR}

A contaminação dos alimentos, como, por exemplo, o ovo, ocorre principalmente devido à necessidade de fazer uso de substâncias químicas que administradas aos animais, aplicadas aos locais de alojamento ou adicionadas à alimentação das aves podem ser detectadas no produto final destinado ao consumo por animais e, principalmente, pelos seres humanos. Estas substâncias químicas são caracterizadas como aditivos alimentares e no caso dos praguicidas são chamados de aditivos alimentares não intencionais por serem resultado do meio ambiente de produção do alimento (HAYES; CAMPBELL, 1986).

Os aditivos alimentares não intencionais consistem em uma classe de substâncias químicas que não são naturais dos alimentos ou de um propósito de 
produção tecnológica. Uma variada série de caminhos, incluindo o meio ambiente onde o alimento foi produzido, processado e armazenado, é responsável pela presença dessas substâncias nos alimentos.

O número total de substâncias químicas que podem contaminar os alimentos é desconhecido, porém pode variar de acordo com a técnica agropecuária empregada.

Nos animais existem duas fontes principais de contaminação dos alimentos produzidos por eles: 1. Produtos de uso veterinário e 2. Produtos utilizados na alimentação. Em geral os produtos utilizados na dieta dos animais ou de uso veterinário devem ser suspensos ou administrados antes da comercialização do alimento. Estima-se que $100 \%$ das aves recebam alimento com suplemento de antibióticos, nos Estados Unidos da América - EUA - (HAYES; CAMPBELL, 1986) e que $80 \%$ da proteína animal consumida neste país sejam provenientes de animais que foram expostos a estes alimentos ou medicamentos. O único problema na determinação do potencial de perigo a saúde humana associada à presença dessas substâncias é o fato delas poderem ser biotransformadas nos animais, formando um grande número de metabólitos com estrutura molecular diferente da original e de toxicidade elevada. Sabe-se que nos organismos animais as moléculas químicas geralmente são oxidadas, o que facilita a sua hidrossolubilidade, e que pode acarretar em uma diminuição da toxicidade, porém o inverso também pode ocorrer, formando substâncias mais tóxicas para o ser vivo. Desta forma, nos produtos de origem animal pode-se encontrar não apenas a molécula original, bem como os metabólitos conjugados ou não e os resíduos, conjugados ou não.

A presença de possíveis substâncias químicas nos alimentos de origem animal dificilmente irá causar danos toxicológicos agudos quando este alimento for 
consumido, porém níveis de resíduos de alguns produtos como os praguicidas podem causar problemas após a exposição crônica. Este conceito está relacionado àquele de carcinogenicidade, um dos principais fatores quando se trata de praguicidas, principalmente devido ao efeito cumulativo destas substâncias. Este efeito está diretamente associado aos valores de resíduos de praguicidas encontrados nos alimentos que estão associados aos limites máximos de resíduos (LMR); esses tiveram suas origens no inicio do século passado. Em 1906, nos EUA o The Pure Food and Drug Act elaborou a primeira lei nacional sobre a segurança dos alimentos (HAYES; CAMPBELL, 1986). Em 1938, a partir desse primeiro, criouse o Food and Drug Cosmetics e, em 1954, surgiu o primeiro tratado quanto ao controle de resíduos de praguicidas estabelecendo os LMRs (HAYES; CAMPBELL, 1986). Desta forma, iniciou-se o conceito de qualidade dos alimentos que tem grande valor econômico e que atualmente é uma barreira importante no agronegócio mundial.

Atualmente alguns protocolos de estudo vêm sendo elaborados pela Organização Mundial de Saúde (OMS ou WHO - World Health Organization) para serem utilizados pelos diversos países com a intenção de garantir uma dieta segura, isto é, "livre de contaminantes tóxicos", como os praguicidas. Uma das colocações do grupo de estudos GEMS/FOOD (Global Environment Monitoring System/Food Contamination Monitoring and Assessment) estabelecido pela OMS é que os países devem fazer estudos de monitorização dos alimentos e que os resultados obtidos devem ser comparados aos padrões nacionais e internacionais existentes. Nestes estudos, um fator importante que deve ser considerado quanto à contaminação de alimentos é a Ingestão Diária Aceitável (IDA) das substâncias químicas, que podem 
contaminar os alimentos e que deve ser levado em conta quando se estudam praguicidas (WHO, 2005).

A IDA considera a exposição dos indivíduos às substâncias químicas presentes nos alimentos durante toda a vida e este valor deve ser utilizado no estabelecimento do LMR de um praguicida para um determinado alimento. Quando se trata de IDA e LMR nos alimentos, surge o conceito de análise de risco. De acordo com o Codex Alimentarius (FAO/WHO, 2001) os critérios básicos a serem avaliados na análise de risco são: 1. Identificação do perigo; 2. Caracterização do perigo; 3. Exposição e contribuição e 4. Caracterização do risco.

Dentro da identificação do risco para produtos de origem animal destacam-se os resíduos de medicamentos de uso veterinário e aqueles que alteram a produção animal, também chamados de aditivos zootécnicos ou promotores de crescimento (PALERMO NETO, 2006). Os LMRs são estabelecidos pelo equivalente da substância estudada e, por razões práticas, a exposição do consumidor considera o total dos resíduos de aspecto toxicológicos significantes derivados da biotransformação da substância no animal. Há duas exceções a regra: quando a substância gera resíduos ligados e quando a contribuição do risco está claramente definida em efeito farmacológico adverso.

A caracterização do perigo é feita com base nos estudos farmacológicos realizados em animais de laboratório, nos quais é identificada a correlação entre a dose administrada e o efeito observado, sendo escolhido o "nível" onde não se observa efeito toxicológico adverso aos animais de laboratório, isto é, NOEL (No Observed Effect Level). Para os seres humanos o fator de segurança é geralmente de 100 vezes (10 vezes a chance do ser humano ser mais sensível do que o mais 
sensível dos animais de laboratório e 10 vezes da variabilidade genética), caso não seja possível estabelecer a NOEL, não se estabelece a IDA.

Contribuição da exposição é estabelecida através da dieta alimentar e da estimativa da exposição do consumidor. A exposição está relacionada ao consumo diário de diferentes alimentos e a quantidade de resíduos de praguicidas presentes nos mesmos. Assim, a severidade ou potencial de efeitos adversos à saúde do consumidor é chamado de caracterização do risco.

Seguindo com a avaliação de risco, os praguicidas geralmente são classificados como carcinogênicos químicos, pois podem induzir ou produzir a formação de câncer. A exposição humana aos praguicidas veiculados pelos alimentos acontece quando estes são incorporados ao alimento, ou ao meio ambiente por diversas vias e que, desta forma, podem contaminar o suprimento de alimentos durante a sua produção agropecuária, o processamento, o armazenamento e a embalagem.

De acordo com a natureza química, os praguicidas organofosforados, carbamatos e piretróides são aqueles chamados de ligeiramente residuais, pois podem permanecer no ambiente de 1 a 12 semanas, seguidos dos herbicidas derivados da uréia que permanecem no ambiente de 1 a 18 meses e, finalmente, pelos organoclorados que são chamados de altamente residuais podendo permanecer no ambiente por 2 a 5 anos (MÍDIO; MARTINS, 2000).

Após o estabelecimento da IDA e com base nos aspectos toxicológicos e avaliação de risco dos praguicidas, os resultados podem ser utilizados para o estabelecimento dos LMRs para cada praguicida nos diferentes alimentos.

Os LMRs são resultados dos estudos de campo, observadas as Boas Práticas Agrícolas (BPA) e por conseqüência o resíduo remanescente do praguicida é 
adotado como valor para a cultura estudada. Quando a somatória dos valores dos LMRs de um praguicida para os diferentes tipos de alimentos resultar em um valor inferior a IDA, os LMRs encontrados podem ser utilizados. Se a somatória ultrapassar a IDA deve-se escolher quais culturas poderão ser produzidas com o uso do praguicida.

A avaliação toxicológica do praguicida é feita a partir do valor da IDA do praguicida e dos LMRs, sendo chamado de Ingestão Diária Teórica Máxima (IDTM) do praguicida (GEMS/FOOD, 1997). Assim, tem-se:

IDTM $=\sum L M R \times F_{1}$

Onde: LMR = limite máximo de resíduos estabelecido pela legislação nacional ou a quantidade de um resíduo encontrada na amostra analisada.

$\mathrm{F}_{1}=$ consumo per capita de um alimento/dia de acordo com dados de consumo obtidos do IBGE, 2004.

A IDTM é calculada em $\mathrm{mg} /$ pessoa/dia ou em mg/peso corpóreo/dia, sendo considerado no Brasil o uso de $60 \mathrm{~kg}$ para um indivíduo adulto e como $20 \mathrm{~kg}$ para uma criança.

A partir do cálculo da IDTM é possível verificar a contribuição do praguicida na dieta alimentar, sendo que, para a segurança do consumidor, deve-se considerar como sendo a $\%$ IDA $<100$.

No Brasil, atualmente para o estabelecimento de LMR, estes estudos toxicológicos estão sendo levados em consideração. De acordo com o Decreto no. 98.816, de 11 de janeiro de 1990, resíduo de praguicida é "a substância ou mistura de substâncias remanescentes ou existentes em alimentos ou no meio ambiente, decorrente do uso ou não de agrotóxicos e afins, inclusive qualquer derivado específico, tais como produtos de conversão e de degradação, metabólitos, produtos 
de reação e impurezas, considerados toxicológica e ambientalmente importantes". Internacionalmente, o Codex Alimentarius (FAO/WHO, 1993) descreve o LMR como sendo a concentração máxima de um resíduo de praguicida (expressa em mg/kg) legalmente permitida em uma cultura ou ração animal e recomendada pela Comissão do Codex Alimentarius. O LMR é baseado nas Boas Práticas de Campo (BPC ou GAP - Good Agricultural Practices) no qual o alimento proveniente destes estudos gera resultados onde se estabelece o LMR. Os valores de LMR estabelecidos pelo Codex Alimentarius são utilizados primeiramente no comércio internacional e são derivados de estimativas feitas pelo grupo de analistas de resíduos de praguicidas (JMPR - Joint Member of Pesticide Residues). Segundo o JMPR deve-se observar o valor do resíduo de praguicida e sua contribuição toxicológica e deve ser feita revisão dos estudos de resíduos em ensaios de campo supervisionado, incluindo os estudos que refletem em BPC nacionais. Os dados resultantes de estudos de campo onde a maior dose nacional (recomendada, autorizada ou registrada) foi utilizada são incluídos nesta revisão. Para acomodar as variações nacionais nos requisitos para controle de pragas o Codex Alimentarius leva em consideração os níveis dos estudos de campo que são considerados efetivamente representativos.

Atualmente, outro fator tem sido levado em consideração quando se trata da saúde do consumidor, é a Dose Aguda de Referência (RDf - Reference Dosage factor), que corresponde a uma quantidade de substância química presente em um alimento e/ou água de beber, normalmente expresso em peso corpóreo, que pode ser ingerido em um período de $24 \mathrm{~h}$ ou menos sem que cause risco apreciável a saúde do consumidor. A RDf vêm sendo estabelecida como o limite saudável de segurança, quanto ao risco à saúde, isto é, quando os valores encontrados estão 
abaixo do RDf não há risco de exposição aguda aos resíduos, principalmente para os praguicidas.

A exposição aos resíduos de praguicidas é considerada um fator importante para a saúde do consumidor. Sabe-se que os indivíduos expõem-se por meio dos alimentos e também por outros produtos que possam conter praguicidas, como por exemplo, xampus. Desta forma, a questão sobre o LMR ser seguro ou não está relacionada principalmente aos estudos de monitoramento de resíduos de praguicidas nos alimentos.

\subsection{PRAGUICIDAS}

O uso dos praguicidas, principalmente na agropecuária intensiva, a repetição de cultivos em uma mesma área e o uso inadequado em animais de produção para o combate de pragas e doenças, principalmente aquelas transmitidas por vetores, tem levado a um desequilíbrio biológico, diminuindo o número de algumas espécies de seres vivos, assim como contaminando o meio ambiente.

Um dos primeiros praguicidas utilizados pelo homem foi o enxofre há 2700 anos. O uso deste composto favoreceu o aparecimento do sulfato de cobre que foi inicialmente utilizado no continente europeu por volta de 1800 para o combate de fungos. Além do enxofre, as piretrinas, extraídas do crisântemo foram utilizadas como praguicidas por volta de 1885. Com a expansão da agropecuária, outros compostos foram surgindo e em 1931 passou-se a estudar as características fungicidas dos ditiocarbamatos (DIERKSMEIER, 2001).

Os inseticidas e/ou acaricidas organoclorados, organofosforados e carbamatos são chamados de inseticidas de segunda geração e surgiram na década 
de 1930, sendo o DDT um dos principais representantes dos organoclorados que teve seu uso introduzido como praguicida a partir de 1939. O DDT foi muito utilizado durante a $2^{\mathrm{a}}$. Guerra Mundial no combate de vetores e, posteriormente, foi levado a agricultura e também a pecuária (HUTSON; ROBERTS, 1985). Devido ao sucesso do DDT, outras moléculas de organoclorados foram desenvolvidas, como o aldrim, dieldrim, endrim, clordano e heptacloro. Os organoclorados devido a sua persistência no meio ambiente, ainda podem ser encontrados sendo de grande importância os estudos de resíduos nos alimentos. Entre os outros organoclorados, o $\mathrm{HCH}$ ainda pode estar presente em alimentos como o leite, principalmente devido ao uso em campanhas sanitárias, sendo que, Ciscato et al. (2000) detectaram a presença deste praguicida em amostras de leite comercializado na cidade de São Paulo.

Um aspecto importante, principalmente para os praguicidas organoclorados, é que em aves estes produtos alteram o metabolismo de cálcio fazendo com que os ovos produzidos por estes animais apresentem uma espessura menor da casca, assim a mesma fique frágil e quebradiça, prejudicando o desenvolvimento do embrião. Os hormônios esteróides também podem ser alterados na presença de praguicidas organoclorados, uma vez que estes agem no metabolismo animal como indutores das enzimas microssomais hepáticas.

Quanto aos praguicidas organofosforados, estes tiveram como seu primeiro representante o inseticida parationa, que foi sintetizado em 1944. Os organofosforados têm como vantagem um grande número de variações em sua estrutura química em torno do fósforo, o que confere uma série de diferenças nas propriedades físico-químicas, estabilidade e seletividade. Essas características 
favoreceram o emprego dos organofosforados na agricultura e pecuária, principalmente devido à pronta degradação no meio ambiente (HUTSON, 1985).

Entre os praguicidas carbamatos, o primeiro inseticida sintetizado foi 0 carbaril em 1953. Assim como os organofosforados, sua estabilidade e seletividade são favoráveis para o seu emprego na agropecuária, pois são mais seguros para o meio ambiente e a saúde dos animais, quando comparados aos organoclorados.

Os inseticidas de $3^{a}$ geração são classificados em inseticidas reguladores de crescimentos de insetos, como, por exemplo, o Bacillus thuringiensis e os inseticidas piretróides.

Os inseticidas piretróides são facilmente biotransformados no organismo e, desta forma, há poucas evidências que sugiram uma toxicidade crônica para estes compostos. Por serem ésteres, são compostos facilmente biodegradados no meio ambiente deixando assim poucos resíduos nos alimentos.

Quanto aos fungicidas, estes apresentam várias classificações e em geral baixo risco de intoxicação e contaminação para o meio ambiente. Deve-se salientar, porém, que uma das principais características de muitos fungicidas é a mutagenicidade.

Um grupo de grande importância, devido ao uso acentuado na agricultura, são os herbicidas. Uma das substâncias mais antigas utilizadas com o propósito de combater ervas daninhas foi o sal comum (PFLANZENSCHUTS, 1983). As plantas daninhas competem com a planta que se deseja cultivar e, por isso, há necessidade de combater seu crescimento. Apenas em 1940, após a descoberta do 2,4,D, o uso de herbicidas na agricultura passou a ser mais intenso. 
Os herbicidas, assim como os fungicidas, são classificados em vários grupos que diferem quanto à natureza química e também o modo de ação sobre o organismo alvo (KLINGMAN et.al., 1975).

Dentro do panorama mundial quanto ao consumo de praguicidas, o Brasil ocupa o $8^{\circ}$ lugar no mundo com $3,2 \mathrm{~kg} / \mathrm{ha}$ (CARBONE et al., 2005). Os praguicidas são divididos também em diferentes classes, que são numeradas de I a IV de acordo com o grau toxicológico do maior (I) para o menor (IV) e as vendas no país estão distribuídas da seguinte maneira: classe III > II > IV > I (CARBONE et al., 2005). O emprego amplo dos praguicidas, ao lado de vantagens para a agropecuária, pode acarretar sérios problemas à saúde humana e animal. A presença de resíduos tóxicos nos alimentos e no meio ambiente têm como causa principal o uso incorreto destes produtos, aliado ao fato de muitos serem altamente persistentes e resistentes aos processos de degradação, permanecendo no meio ambiente por muitos anos (CASSARET; DOULLS, 1986).

Quanto aos grupos de praguicidas comercializados no país há um total de 278 ingredientes ativos, sendo que os mais vendidos são os herbicidas com 81 ingredientes ativos representando $29,1 \%$ das vendas, seguido dos inseticidas com 79 ingredientes ativos (28,4\% das vendas); fungicidas com 72 ingredientes ativos (25,0\% das vendas); os "outros" 30 ingredientes ativos (10,8\% das vendas) e acaricidas com 16 ingredientes ativos (5,8\% das vendas) (CARBONE et al., 2005).

A partir da consulta na base de dados da ANVISA (Agência Nacional de Vigilância Sanitária) e do Codex Alimentarius foi possível destacar quais os produtos que têm LMR estabelecidos em ovos e milho, sendo este último um dos principais alimentos destinados à ração dos animais de produção, principalmente aves, correspondendo a $66 \%$ do total de alimento ingerido por elas (BARBOSA et al., 
2007). É importante comentar que os LMRs existentes no Brasil e no Codex Alimentarius são provenientes de estudos encaminhados pelas empresas produtoras de praguicidas no momento em que são efetuados os registros destes produtos no país. Estes LMRs têm uma validade determinada devendo ser reavaliados periodicamente. Os valores não correspondem obrigatoriamente apenas aos produtos comercializados no momento e sim aos produtos que foram estudados e que tiveram seus resultados encaminhados para as agências responsáveis pelo estabelecimento de LMR e de seus registros no país. Os dados de LMR estabelecidos para ovo e produtos vegetais encontram-se na Tabela 2.

Tabela 2 - Praguicidas com Limites Máximos de Resíduos (LMRs), em mg/kg, estabelecidos pelo Brasil e Codex Alimentarius e respectivos LMR em ovo e milho (continua)

\begin{tabular}{lcccc}
\hline \multirow{2}{*}{ Praguicidas } & \multicolumn{2}{c}{ Brasil } & \multicolumn{2}{c}{ Codex } \\
\cline { 2 - 4 } & Milho & Ovo & Milho & Ovo \\
\hline acefato & $*$ & & 0,01 \\
acetato de (Z,E) 9, 12 tetradicadienil & $*$ & & & \\
acetato de (Z)11, hexadicenila & $*$ & & & \\
acetato de (Z) 7, dodecinila & $*$ & & & \\
acetato de (Z) tetradicenila & 0,1 & & & \\
acetocloro & $*$ & & & \\
ácido giberélico & $*$ & & & \\
ácido 4 indol 3 ilbutírico & 0,2 & & \\
alacloro & & & \\
aldicarbe & & & \\
aldrim & 0,04 & & \\
ametrina & 0,02 & & \\
amicarbazona & 0,02 & & \\
amicarbazona & 0,25 & & \\
atrazina & & & & \\
\end{tabular}


(continuação)

\begin{tabular}{|c|c|c|c|c|}
\hline \multirow{2}{*}{ Praguicidas } & \multicolumn{2}{|c|}{ Brasil } & \multicolumn{2}{|c|}{ Codex } \\
\hline & Milho & Ovo & Milho & Ovo \\
\hline azoxistrobina & 0,01 & & & \\
\hline Bacillus thuringiensis & * & & & \\
\hline benfurocarbe & 0,05 & & & \\
\hline bentazona & 0,02 & & 0,2 & 0,05 \\
\hline bifentrina & 0,7 & & 0,05 & 0,01 \\
\hline bitertanol & & & & 0,01 \\
\hline butóxido de piperonila & & & & 1,00 \\
\hline captana & 2,0 & & & \\
\hline carbaril & & 0,50 & 0,02 & \\
\hline carbendazim & 0,05 & & & 0,05 \\
\hline carbofurano & 0,1 & & 0,05 & \\
\hline carbosulfano & 0,05 & & 0,05 & 0,05 \\
\hline carboxim & 0,05 & & & \\
\hline lambda cialotrina & 0,05 & & & \\
\hline cianazina & 0,02 & & & \\
\hline ciflutrina & 0,01 & & 0,05 & \\
\hline beta ciflutrina & 0,05 & & & \\
\hline cinetina & * & & & \\
\hline cipermetrina & 0,05 & & 0,05 & 0,05 \\
\hline alfa cipermetrina & 0,01 & & & \\
\hline beta cipermetrina & 0,05 & & & \\
\hline zeta cipermetrina & 0,05 & & & \\
\hline ciprodinil & & & & 0,01 \\
\hline ciproconazol & 0,01 & & & \\
\hline ciromasina & & 0,25 & & 0,20 \\
\hline cletodim & & & & 0,05 \\
\hline clofentezina & & & & 0,05 \\
\hline clomazona & 0,05 & & & \\
\hline
\end{tabular}


(continuação)

\begin{tabular}{|c|c|c|c|c|}
\hline \multirow{2}{*}{ Praguicidas } & \multicolumn{2}{|c|}{ Brasil } & \multicolumn{2}{|c|}{ Codex } \\
\hline & Milho & Ovo & Milho & Ovo \\
\hline clordane & & & 0,02 & 0,02 \\
\hline clorfenapir & 0,05 & & & \\
\hline clorfluazurom & 0,01 & & & \\
\hline clorpirifós & 0,1 & & 0,05 & 0,01 \\
\hline clorpirifós-metílico & & & & 0,05 \\
\hline clorfentazona etílica & 0,05 & & & \\
\hline clormequat & & & & 0,10 \\
\hline clotiamidina & 0,02 & & & \\
\hline cromafenozida & 0,1 & & & \\
\hline deltametrina & 1,0 & & & 0,02 \\
\hline DDT & & & & 0,1 \\
\hline diazinona & & & 0,02 & 0,02 \\
\hline dicofol & & & & 0,05 \\
\hline dieldrim & & & & 0,1 \\
\hline diflubenzuron & 0,2 & & & 0,05 \\
\hline dimetenamida & 0,01 & & & \\
\hline dimetenamida $\mathrm{P}$ & 0,01 & & 0,01 & 0,01 \\
\hline dimetipim & & & & 0,01 \\
\hline dimetipim & & & & 0,01 \\
\hline dimetoato & & & & 0,05 \\
\hline dimetoxibenzeno & * & & & \\
\hline diquat & & & 0,05 & 0,05 \\
\hline $2,4, D$ & 0,2 & 0,05 & 0,05 & 0,01 \\
\hline dissulfotom & & & 0,02 & 0,02 \\
\hline ditiocarbamato & 0,3 & & & 0,05 \\
\hline diurom & 0,05 & & & \\
\hline endossulfam & & & 0,1 & \\
\hline enxofre & * & & & \\
\hline epoxiconazol & 0,05 & & & \\
\hline esfenvalerato & 1,0 & & & 0,01 \\
\hline
\end{tabular}


(continuação)

\begin{tabular}{|c|c|c|c|c|}
\hline \multirow{2}{*}{ Praguicidas } & \multicolumn{2}{|c|}{ Brasil } & \multicolumn{2}{|c|}{ Codex } \\
\hline & Milho & Ovo & Milho & Ovo \\
\hline espinosade & 0,01 & & & 0,01 \\
\hline etefom & & & & 0,20 \\
\hline etiona & & 0,20 & & \\
\hline etofenproxi & 0,05 & & & \\
\hline famoxadona & & & & 0,01 \\
\hline fenamifós & & & & 0,01 \\
\hline fenbuconazol & & & & 0,05 \\
\hline fenitrotiona & & & & 0,05 \\
\hline fenpropatrina & 0,4 & & & 0,01 \\
\hline fenpropimorfe & & & & 0,01 \\
\hline fentoato & & & & 0,05 \\
\hline fipronil & 0,01 & & 0,01 & 0,02 \\
\hline floransulfurom & 0,02 & & & \\
\hline fludioxonil & 0,04 & & & 0,05 \\
\hline flumioxazina & 0,05 & & & \\
\hline flusilazol & & & & 0,01 \\
\hline flutolanil & & & & 0,05 \\
\hline forato & 0,05 & & 0,05 & 0,05 \\
\hline fosfeto de magnésio & * & & & \\
\hline fosfina & 0,1 & & & \\
\hline furotiocarbe & 0,03 & & & \\
\hline glifosato & 0,1 & & 5,0 & 0,05 \\
\hline glufosinato de amônia & 0,05 & & 0,1 & 0,05 \\
\hline haloxiflope & & & & 0,01 \\
\hline heptacloro & & & & 0,05 \\
\hline imazapique & 0,1 & & & \\
\hline imazapir & 0,1 & & & \\
\hline imidacloprido & 0,5 & & & 0,02 \\
\hline indoxacarbe & 0,2 & & & 0,01 \\
\hline iodossulfurom sódico & 0,01 & & & \\
\hline
\end{tabular}


(continuação)

\begin{tabular}{|c|c|c|c|c|}
\hline \multirow{2}{*}{ Praguicidas } & \multicolumn{2}{|c|}{ Brasil } & \multicolumn{2}{|c|}{ Codex } \\
\hline & Milho & Ovo & Milho & Ovo \\
\hline isoxaflutol & 0,01 & & & \\
\hline lindano & & & 0,01 & 0,01 \\
\hline linurom & 0,3 & & & \\
\hline lufenurom & 0,05 & & & \\
\hline malationa & $8,0^{*}$ & & 0,05 & \\
\hline metalacloro & 0,02 & & & \\
\hline s-metalacloro & 0,1 & & & \\
\hline metalaxil & 0,05 & & & \\
\hline metamidofós & & & & 0,01 \\
\hline metidationa & & & 0,1 & 0,02 \\
\hline 4,8 metil decanol & * & & & \\
\hline metiocarbe & & & 0,05 & 0,05 \\
\hline metomil & 0,1 & & 0,02 & 0,02 \\
\hline metoprene & & & & 0,02 \\
\hline metoxifenozide & 0,5 & & 0,02 & 0,01 \\
\hline mezatriona & 0,01 & & & \\
\hline miclobutanil & & & & 0,01 \\
\hline monocrotofós & & & & 0,02 \\
\hline nicosulfurom & 0,1 & & & \\
\hline novalurom & 0,02 & & & 0,01 \\
\hline oxamil & & & & 0,02 \\
\hline óxido de fenbutatin & & & & 0,05 \\
\hline paraquate & 0,1 & & 0,3 & 0,005 \\
\hline paration-metílico & 0,1 & & & \\
\hline penconazol & & & & 0,05 \\
\hline pendimetalina & 0,1 & & & \\
\hline permetrina & 0,1 & & & 0,10 \\
\hline piraclostrobina & 0,1 & & 0,02 & 0,05 \\
\hline piridafentiona & 0,05 & & & \\
\hline pirimicarbe & & & & 0,05 \\
\hline
\end{tabular}


(conclusão)

\begin{tabular}{|c|c|c|c|c|}
\hline \multirow{2}{*}{ Praguicidas } & \multicolumn{2}{|c|}{ Brasil } & \multicolumn{2}{|c|}{ Codex } \\
\hline & Milho & Ovo & Milho & Ovo \\
\hline pirimifós-metílico & 10,0 & & & 0,01 \\
\hline procloraz & & & & 0,10 \\
\hline profenofós & 0,02 & & & 0,02 \\
\hline propargito & & & 0,1 & 0,10 \\
\hline propiconazol & 0,1 & & & 0,05 \\
\hline quintozeno & & & 0,01 & 0,03 \\
\hline setoxidim & 0,3 & & & \\
\hline simazina & & & 0,02 & \\
\hline tebuconazol & 0,1 & & & 0,05 \\
\hline tebufenozida & 0,02 & & & 0,02 \\
\hline terbufós & 0,05 & & 0,01 & 0,01 \\
\hline terbutilazina & 0,1 & & & \\
\hline tiabendazol & 0,2 & & & 0,10 \\
\hline tiametoxam & 0,02 & & & \\
\hline tidiazurom & & 0,10 & & \\
\hline tiodicarbe & 0,1 & & & \\
\hline tolifluanida & 0,5 & & & \\
\hline triadimefom & & & & 0,05 \\
\hline triadimenol & & & & 0,05 \\
\hline triazofós & 0,01 & & & \\
\hline triclorfom & 0,01 & & & \\
\hline trifloxistrobina & 0,05 & & 0,02 & 0,04 \\
\hline trflubenzurom & 0,1 & & & \\
\hline triflumurom & 0,1 & & & \\
\hline trifluralina & 0,05 & & & \\
\hline sulfosato & 0,05 & & & \\
\hline vinclozolina & & & & 0,05 \\
\hline
\end{tabular}

* Grão armazenado - ANVISA, 2007 
Com base nos dados apresentados na Tabela 2 e considerando que o Brasil é um país com grande potencial de consumo de praguicidas, (STEPHENSON; IUPAC 2005), as análises de resíduos de praguicidas em alimentos, em particular, o ovo, são importantes na avaliação da qualidade destes alimentos. Além disso, o ovo apesar de fazer parte da dieta do brasileiro (MATTOS; MARTINS, 2004), há poucos trabalhos relacionados à presença de resíduos de praguicidas neste alimento, sendo que essas informações poderiam auxiliar na avaliação da contribuição dos resíduos de praguicidas na saúde da população.

Dentre os diversos métodos analíticos empregados atualmente para a detecção de resíduos de praguicidas, no presente trabalho foi escolhido o método multirresíduos DFG S19 (THEIR, 1992; MODULAR MULTIPLE REVISED VERSION OF THE DFG METHOD S19, 1999), por ser utilizado em análises oficiais de monitorização de resíduos de praguicidas em alimentos de origem vegetal e animal, estando presente nas diretrizes da Comunidade Européia e do Codex Alimentarius. 
OBJETIVO 


\section{OBJETIVO}

Este estudo tem como propósito avaliar a qualidade do alimento ovo, consumido pela população da cidade de São Paulo, quanto aos resíduos de praguicidas eventualmente presentes. A pesquisa desenvolvida para atender o objetivo desse trabalho é possível graças ao emprego do método analítico DFG S19, que permite a análise simultânea de vários praguicidas. 
MATERIAL E MÉTODO 


\section{MATERIAL E MÉTODO}

\subsection{AMOSTRAS DE OVO}

Foram coletadas 150 amostras de ovo em diferentes supermercados da cidade de São Paulo, durante o período de Outubro de 2003 a Julho de 2005. Os locais de colheita foram supermercados, sacolões, feiras livres e mercearias que são atendidos por distribuidores de ovos, granjeiros e comércio informal.

Os ovos são disponibilizados no comércio em embalagens plásticas, de isopor ou de papelão contendo normalmente $6,12,30$ ou 36 unidades. Para a uniformidade na amostragem seguiu-se recomendação do Codex Alimentarius (FAO/WHO, 1999), no qual cada amostra de laboratório deve conter 12 ovos inteiros ou $500 \mathrm{~g}$.

\subsection{MÉTODO ANALÍTICO}

\subsubsection{Material}

Amostra, solventes, reagentes e soluções padrão de praguicidas.

\subsubsection{Amostra}

As amostras de ovo ao chegarem ao laboratório foram analisadas imediatamente, conservando as características do comércio, onde os ovos ficam 
expostos frescos, em gôndolas ou em bancas. A porção analisada corresponde a clara + a gema após a remoção da casca.

\subsubsection{Solventes}

Todos os solventes utilizados na análise eram "Para Análise de Resíduos" (PAR) e a água bidestilada:

- Acetona, marca Merck e Tedia

- Diclorometano, marca Merck e Tedia

- Acetato de etila, marca Merck e Tedia

- Ciclo-hexano, marca Merck e Tedia

- Isooctano, marca Merck e Tedia

- Hexano, marca Merck e Tedia

- Tolueno, marca Merck e Tedia

\subsubsection{Solutos e outros}

Solutos e outros reagentes eram "Para Análise" (PA).

- Cloreto de sódio anidro, marca Merck - tratado por $2 \mathrm{~h}$ a $550^{\circ} \mathrm{C}$ para a eliminação de interferentes como os ftalatos

- Sulfato de sódio anidro, marca Merck e Tedia tratado por $2 \mathrm{~h}$ a $550^{\circ} \mathrm{C}$ para a eliminação de interferentes como os ftalatos

- Algodão lavado com diclorometano - extração de interferentes com o auxílio do soxlet por $4 \mathrm{~h}$

- sílica gel 60, marca Merck com tamanho da partícula de 0,063 a 0,200 mm, 70 a 230 mesh ASTM - aquecida a $120^{\circ} \mathrm{C} / 3 \mathrm{~h}$ em estufa e desativada com 
$1,5 \%$ de água bidestilada e posterior homogeneização por $2 \mathrm{~h}$ em agitador mecânico.

- coluna para a cromatografia de permeação a gel (GPC) foi preenchida com suporte Bio Beads $®$ SX3, partículas de tamanho 200 a 400 mesh - foi trocado o enchimento a cada 1000 amostras, para o preparo da coluna o gel foi deixado em solução 1:1 de ciclo-hexano/acetato de etila até a formação de um gel uniforme, adicionou-se à coluna de vidro e aplicou-se o fluxo de solvente de $5 \mathrm{~mL} / \mathrm{minuto}$

\subsubsection{Soluções}

As soluções ou misturas de solventes foram preparadas no momento da análise de acordo com a metodologia analítica.

\subsection{Solução para cromatografia de permeação a gel (GPC)}

Preparar a solução 1/1 de acetato de etila/ciclo-hexano no momento de uso.

\subsection{Eluentes da coluna de sílica}

Preparar no momento de uso, medir com auxílio de proveta mantendo as proporções adequadas.

Eluato 01: hexano+tolueno (65:35)

Eluato 02: tolueno (100)

Eluato 03: tolueno+acetona (95:5) 
Eluato 04: tolueno+acetona $(80: 20)$

Eluato 05: acetona (100)

\subsubsection{Padrões}

Os padrões analíticos de referência utilizados para o preparo das soluções mãe, soluções intermediárias e soluções de trabalho possuíam de 95 a 100\% de pureza. Os produtos encontravam-se na forma de pó, cristais ou líquida e a partir desses foram preparadas as soluções de estoque. Essas soluções foram feitas na

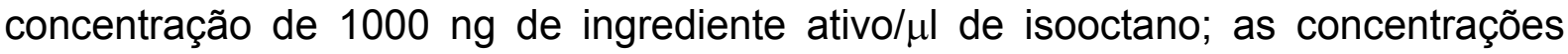
foram determinadas de acordo com o grau de pureza dos padrões analíticos. As soluções estoque foram armazenadas em freezer a $-15^{\circ} \mathrm{C}$.

As soluções de trabalho foram preparadas nas concentrações de $1 \mathrm{ng} / \mu \mathrm{l}$ a $0,01 \mathrm{ng} / \mu \mathrm{l}$ (de acordo com a sensibilidade do detector) e estas foram diluídas em solventes adequados a solubilidade dos produtos estudados e as características dos equipamentos. As soluções de uso diário foram armazenadas em geladeira a aproximadamente $4^{\circ} \mathrm{C}$.

\subsubsection{Aparelhos e acessórios}

- Agitador mecânico - GFL

- Balança analítica - SARTORIUS - Tipo LC 12005 e Tipo MC1

- Balança semi-analítica - SARTORIUS - Tipo ING/6971500

- Bomba de vácuo - PRIMAR/KOHLBACH - Modelo 141

- Cromatógrafos a gás com detectores de captura de elétrons (ECD), nitrogênio/fósforo (NPD), fotométrico de chama (FPD), marcas VARIAN 3400 
e 3400X e HP 6890 com - colunas cromatográficas empacotadas, megabore e capilares de diferentes polaridades

- Destiladores de água - WESTINGHOUSE, modelo 40994

- Dispensadores volumétricos de 1 a $10 \mathrm{~mL}$, marca CRALL

- Estação de trabalho para operação do HP 6890

- Estufa - MEMMERT, Tipo UM 100

- Evaporador rotativo - BUCHI 461 Water Bach, Tipo RE 121, motor KRVITD, com bomba de vácuo - TECNAL, modelo 058; Banho-maria - GFL, Tipo 1042 e resfriador - RMG LAUDA, Tipo RMT6

- Equipamento para cromatografia de permeação a gel (GPC) com bombas LATEK P100 e PHARMACIA LKB - HPLC, modelo 2248, com válvulas Ryodine e loop de $5 \mathrm{~mL}$

- Geradores de nitrogênio (pureza de 99,99\%) - Peak Scientific

Mixer ou homogeneizadores - DUPONT Instruments - Modelo Omni Mixer 17015

- Injetores automáticos, VARIAN 8200 e HP

- Integradores VARIAN 4400 e 4290

- Máquina de lavar vidraria - MIÉLE - MIELABOR G7783 Multitronic, Tipo DOS, modelo C60

- Microseringas com volume de $10 \mu \mathrm{L}$ para injeções nos cromatógrafos, marca SGE e HAMILTON

- Mufla - NABERTHERM, modelo L5/R

- Peras de borracha

- Purificador de água Milli-Q PLUS, marca Milipore

- Seringas de vidro com ponta metálica, volume de $10 \mathrm{~mL}$ para uso no GPC 
- Turbo Vap - concentrador de amostras automático - ZYMARK®

- Ultra-som - BANDELIN - SONOREX RK 100

\subsubsection{Vidraria}

- Balões de fundo redondo com tampa de teflon e capacidade de $500 \mathrm{~mL}$ e $100 \mathrm{~mL}$

- Balões volumétricos de volumes 1,0; 2,0; 4,0; 5,0; 10,0; 25,0; 50,0 e 100 mL e tampa de teflon para armazenamento de padrões analíticos

- Balões de fundo cônico de $50 \mathrm{~mL}$ com tampa de teflon

- Baqueta de vidro

- Béqueres de vários volumes

- Copos de vidro "ball", com tampa de rosca e volume de $500 \mathrm{~mL}$

- Colunas de vidro para purificação com sílica gel (diâmetro interno de 0,8 mm x altura de $150 \mathrm{~mm}$ e extremidade com diâmetro interno de 0,7 $\mathrm{mm} x$ altura de $95 \mathrm{~mm})$

- Colunas de vidro para o GPC com $70 \mathrm{~cm}$ de tamanho e 4,0 cm de diâmetro interno

- Erlenmeyer de vários tamanhos

- Frasco tipo "SHOT" de $250 \mathrm{~mL}$ para armazenamento de amostras homogeneizadas

- Funil de vidro

- Micropipetas de 20,0; 50,0 e 100,0 $\mu \mathrm{L}$, marca BRAND e volume ajustável de 150,0 até $1000,0 \mu \mathrm{L}$, marca FORTUNA

- Provetas de vários tamanhos: 5,0; 10,0; 50,0; 100,0; 500,0 mL

- Pipetas volumétricas de 0,5; 1,0; 2,5; 5,0 e 10,0 mL 
- Soxlet - condensador em espiral (fluxo de água contínuo) acoplado a vidro com boca esmerilhada e balão de fundo redondo com capacidade para 500 $\mathrm{mL}$; banho-maria com temperatura controlada em $40^{\circ} \mathrm{C}$

- Tubos de vidro graduados com volume de $10 \mathrm{~mL}$ e tampa de teflon

\subsubsection{Extração}

Nesta etapa todos os possíveis praguicidas presentes na amostra devem ser retirados da mesma e transferidos para o solvente extrator. Fatores importantes a serem considerados nesta etapa em metodologias multirresíduos, em especial para produtos de origem animal, é a quantidade de alíquota a ser utilizada, além da quantidade de gordura presente na amostra, uma vez que existem praguicidas apolares, portanto, com maior afinidade a fase lipídica. A etapa de extração também deve ser eficiente para extrair aqueles com afinidade a fase aquosa, ou seja, os polares.

Para o método multirresíduos DFG-S19 optou-se por trabalhar com $20 \mathrm{~g}$ de amostra, o que corresponde aproximadamente $2,3 \mathrm{~g}$ de gordura em um peso total de ovo. Esta quantidade possibilitou o emprego do método de forma adequada e a retirada completa dos praguicidas em especial àqueles com maior afinidade a fase apolar como os organoclorados.

Para que durante a etapa de extração os praguicidas polares pudessem ser extraídos da melhor maneira de forma adequada, a nova versão do DFG S19 que é o L00.00-34 descreve oito diferentes processos de extração e para amostras com níveis de gordura e água, tais quais, aqueles existentes nos ovos, uma porção de cloreto de sódio é adicionado à amostra para que o conjunto "água + solvente 
extrator" tenha uma melhor saturação, favorecendo a recuperação dos compostos polares. Possíveis interferentes presentes nos reagentes, como os ftalatos podem fornecer resultados inadequados à análise foram retirados após o tratamento a temperaturas de $500^{\circ} \mathrm{C}$ por pelo menos $2 \mathrm{~h}$ em mufla (ANASTASIADES; LEHOTAY, 2003).

Para a amostragem de ovo, retirou-se a casca dos ovos e misturou-se a clara e a gema até a completa homogeneização. Do homogeneizado, uma alíquota de 20 g de ovo foi pesada e acrescentou-se quantidade de água suficiente para manter a proporção 2:1 de solvente orgânico e água, sabe-se que em média $50 \mathrm{~g}$ de ovo apresentam $37,4 \mathrm{~g}$ de água e $5,28 \mathrm{~g}$ de gordura. $\mathrm{O}$ solvente orgânico extrator empregado foi a acetona. A amostra foi agitada por pelo menos 15 minutos em agitador mecânico a 110 rpm.

\subsubsection{Partição}

$\mathrm{Na}$ etapa de partição os possíveis praguicidas são transferidos do solvente extrator, a acetona, para aqueles mais compatíveis à etapa de purificação. Após a extração com acetona, adicionou-se cloreto de sódio (tratado a $500^{\circ} \mathrm{C} / 2 \mathrm{~h}$ ) e solução do GPC, nesta etapa a amostra foi agitada por mais 5 minutos e deixada em repouso para que ocorresse a completa separação das fases. A fase orgânica (sobrenadante) foi recolhida em um béquer e a ela adicionou-se sulfato de sódio anidro (tratado a $500^{\circ} \mathrm{C} / 2 \mathrm{~h}$ ) que é utilizado para facilitar a retirada de água do extrato. Agitou-se o extrato com o auxílio de uma baqueta e deixou-se em repouso por mais 5 minutos. Recolheu-se em proveta o equivalente a $100 \mathrm{~mL}$ do extrato. $\mathrm{O}$ extrato foi filtrado em funil de vidro com uma rolha de algodão e sulfato de sódio 
anidro. Lavou-se o sulfato de sódio com duas porções de $10 \mathrm{~mL}$ de solução do GPC e coletou-se todo o filtrado em balão de fundo redondo. O filtrado foi levado para o evaporador rotativo para concentração até atingir volume aproximado de $2 \mathrm{~mL}$. Foi estabelecida a temperatura de $40^{\circ} \mathrm{C}$ para o banho-maria do evaporador rotativo, rotação de 100 rpm e pressão na bomba de 55 PSI para a concentração do extrato da amostra. Nestas condições os possíveis praguicidas não são transportados junto com os solventes que estão evaporando. O extrato concentrado foi evaporado a secura em fluxo suave de nitrogênio. Neste momento o extrato seco está pronto para a etapa de purificação ou se houver necessidade pode ser armazenado em geladeira.

\subsubsection{Purificação}

A etapa de purificação consiste na retirada de possíveis interferentes da amostra como, por exemplo, gordura, carboidratos, pigmentos etc. A purificação é uma etapa muito importante, principalmente para análises por metodologias multirresíduos onde vários praguicidas são estudados principalmente por cromatografia gasosa, com especial atenção ao uso do detector de captura de elétrons (ECD) que possui grande sensibilidade e a presença destas substâncias pode prejudicar a análise dos compostos de interesse.

A cromatografia de permeação a gel ou cromatografia por exclusão é um método bastante utilizado na purificação de amostras. Esta técnica separa as substâncias de interesse daquelas de elevado peso molecular. Os tipos da fase estacionária e da fase móvel é que vão determinar quais moléculas que serão 
excluídas. No método empregado neste trabalho a fase estacionária é o gel BIO BEADS $₫ S X 3$ e a fase móvel é a mistura (1:1) de ciclo-hexano+acetato de etila.

Para a purificação com o emprego do GPC foi adicionado ao extrato seco, 15 $\mathrm{mL}$ de solução ciclo-hexano+acetato de etila (1:1) e um pouco da mistura de cloreto de sódio anidro + sulfato de sódio anidro para a retirada de possível vestígio de água. O extrato foi filtrado novamente em sulfato de sódio e todo o volume foi recolhido com o auxílio de seringa de vidro de $10 \mathrm{~mL}$ de capacidade e ponteira de metal. A seguir filtrou-se em membrana filtrante PTFE e injetou-se no GPC.

\subsubsection{Condições de operação do GPC}

- Ajustar o volume de $5 \mathrm{~mL}$ por minuto;

- Deixar a válvula na posição load para carregar a amostra para dentro do loop (5 mL);

- Injetar a amostra;

- Descartar os primeiros 5 minutos da corrida;

- Recolher em balão de fundo redondo os próximos 40 minutos da corrida;

- Deixar lavando o sistema por 5 minutos e descartar a solução.

Após a eluição no GPC o eluato recolhido foi concentrado no evaporador rotativo, temperatura do banho-maria a $40^{\circ} \mathrm{C}$, rotação de $100 \mathrm{rpm}$ e pressão de 55PSI. Concentrou-se até o volume aproximado de $2 \mathrm{~mL}$ e levou-se para secura completa em fluxo suave de nitrogênio.

O extrato seco obtido após o GPC sofreu uma nova purificação, agora em mini-coluna de sílica gel desativada a 1,5\% de água. Esta nova etapa de purificação 
teve como eluentes, várias misturas de solventes, onde, alterando-se a polaridade ocorreu uma separação inicial dos possíveis praguicidas presentes na amostra.

A purificação com mini-coluna de sílica gel necessita que seja eliminado completamente qualquer vestígio do acetato de etila do extrato seco. O solvente orgânico, acetato de etila, altera as características da sílica gel desativada a 1,5\% de água formando mais sítios ativos e fazendo com que a eluição dos praguicidas seja diferente daquela já estudada, prejudicando assim a identificação dos mesmos.

Para a retirada do acetato de etila remanescente no extrato seco, efetuou-se a concentração com isooctano no evaporador rotativo, manteve-se a temperatura de $40^{\circ} \mathrm{C}$ e $100 \mathrm{rpm}$, modificando-se apenas a pressão que passou a ser $60 \mathrm{PSI}$. Esta etapa foi realizada por duas vezes para completa retirada do acetato de etila. $\mathrm{O}$ extrato foi concentrado até o volume aproximado de $1 \mathrm{~mL}$.

\subsubsection{Mini-coluna de sílica gel}

\subsection{Preparo da coluna}

- Dentro da coluna previamente limpa, colocar um tampão de algodão;

- Pesar $1 \mathrm{~g}$ da sílica gel desativada a 1,5\%, adicionar hexano e agitar;

- Permitir que se forme um gel homogêneo;

- Transferir o gel para dentro da coluna, previamente lavada com n-hexano evitando a formação de bolhas de ar;

- Por meio de pequena agitação, auxiliar o assentamento do gel na coluna e ao final colocar $1 \mathrm{~g}$ de sulfato de sódio; 
- Durante todo o procedimento colocar o hexano evitando que o gel fique seco;

- Quando o hexano atingir a altura do sulfato de sódio adicionar com auxílio de pipeta Pasteur $1 \mathrm{~mL}$ da amostra;

- Ao atingir a altura do sulfato de sódio, adicionar $1 \mathrm{~mL}$ de hexano;

- Esperar até atingir o sulfato de sódio;

- Descartar tudo o que foi eluído até o momento;

- Colocar na extremidade da coluna um balão de $10 \mathrm{~mL}$ graduado, com tampa;

- Eluir a coluna com os diferentes eluentes.

\subsection{Preparo dos eluentes}

Com o auxílio de proveta medir os volumes, mantendo a proporção adequada.

Eluente 01: hexano : tolueno $(65 / 35)$

Eluente 02: tolueno (100)

Eluente 03: tolueno : acetona (80/20)

Eluente 04: tolueno : acetona (95/5)

Eluente 05: acetona (100)

\subsection{Eluição da coluna}

- Após a eluição de $1 \mathrm{~mL}$ de hexano, lavar o balão de fundo cônico onde estava a amostra com $2 \mathrm{~mL}$ do eluato 01 ; 
- Recolher o eluente do balão e levar a coluna;

- Recolher o eluato $01 \mathrm{em}$ um tubo de $10 \mathrm{~mL}$ graduado;

- Após os $2 \mathrm{~mL}$ do eluente 01 atingirem o sulfato de sódio adicionar $6 \mathrm{~mL}$ do eluente 01 na coluna e recolher no tubo graduado;

- Proceder igualmente para os eluentes 02, 03 e 04, recolhendo em tubos graduados diferentes;

- No eluente 05, lavar o balão com $2 \mathrm{~mL}$, levar a coluna e lavar mais uma vez o balão de fundo cônico agora com $6 \mathrm{~mL}$ do eluente 05 ;

- Levar a coluna e recolher em tubo graduado;

- Após a eluição de todos os eluentes, completar os volumes dos tubos graduados com os respectivos eluentes e levar para a cromatografia.

\subsubsection{Identificação e quantificação}

Nesta etapa os eluatos provenientes da etapa anterior foram analisados por cromatografia gasosa. Para a análise dos compostos halogenados, utilizou-se cromatografo a gás com detector de captura de elétrons (ECD), para os compostos nitrogenados e com fósforo na molécula utilizou-se o detector de nitrogênio/fósforo (NPD) e para aqueles compostos fosforados mais polares utilizou-se o detector fotométrico de chama (FPD).

As amostras que tiveram resultados positivos, isto é, presença de pico próximo ao tempo de retenção de algum praguicida avaliado naquele equipamento, foi injetada novamente em outro equipamento onde as condições de temperatura de coluna e injetor, sistema de injeção (on column ou splitless) e polaridade de coluna fossem diferentes daquelas onde foi observado o resultado positivo. Para os 
resultados positivos optou-se por fazer estudos de fortificação com o praguicida encontrado nos valores próximos a legislação vigente ou próximo a aquele encontrado na amostra.

\subsubsection{Condições cromatográficas}

\subsection{Cromatógrafo a gás com ECD}

Para a identificação de inseticidas organoclorados, inseticidas piretróides e alguns fungicidas as condições de análise foram: coluna capilar de $30 \mathrm{~m} \times 0,32 \mathrm{~mm}$ diâmetro interno, com 0,25 $\mu \mathrm{m}$ de espessura do filme (SPB ${ }^{\mathrm{TM}}$ 608); programa de temperatura: $90^{\circ} \mathrm{C}$ a $210^{\circ} \mathrm{C}\left(30^{\circ} \mathrm{C} /\right.$ minuto), tempo de espera de 2 minutos, $250^{\circ} \mathrm{C}$ $\left(10^{\circ} \mathrm{C} /\right.$ minuto), tempo de espera de 14 minutos; sistema de injeção splitless a $220^{\circ} \mathrm{C}$, tempo de espera de 2 minutos; temperatura do detector de $300^{\circ} \mathrm{C}$; fluxo de gases: gás de arraste (nitrogênio) $1 \mathrm{~mL} /$ minuto coluna e $29 \mathrm{~mL} /$ minuto make up. A confirmação e quantificação de picos reconhecidos como possíveis praguicidas foi feita em coluna capilar com fases e polaridades diferentes $\left(\mathrm{PTE}^{\mathrm{TM}} 5\right.$ e SPB ${ }^{\mathrm{TM}}$ 1). Também foi utilizado sistema de injeção on column.

\subsection{Cromatógrafo a gás com NPD}

Para a identificação de inseticidas organofosforados, inseticidas carbamatos e alguns herbicidas as condições de análise foram: coluna capilar com $30 \mathrm{~m} \times 0,32$ $\mathrm{mm}$ de diâmetro interno e $0,25 \mu \mathrm{m}$ de espessura no filme (PTE $\left.{ }^{\mathrm{TM}} 5\right)$; o programa de temperatura utilizado foi: $80^{\circ} \mathrm{C}$ a $200^{\circ} \mathrm{C}\left(30^{\circ} \mathrm{C} /\right.$ minuto $)$, tempo de espera de 2 
minutos, $230^{\circ} \mathrm{C}\left(15^{\circ} \mathrm{C} /\right.$ minuto), tempo de espera de 6 minutos, $250^{\circ} \mathrm{C}\left(5^{\circ} \mathrm{C} /\right.$ minuto $)$, tempo de espera de 2 minutos; sistema de injeção splitless a $200^{\circ} \mathrm{C}$, tempo de espera de 2 minutos; temperatura do detector: $300^{\circ} \mathrm{C}$; fluxo de gases: gás de arraste (nitrogênio) $1 \mathrm{~mL} /$ minuto e $29 \mathrm{~mL} /$ minuto make up, hidrogênio: $4,5 \mathrm{~mL} /$ minuto, ar sintético $175 \mathrm{~mL} /$ minuto. A confirmação e quantificação de picos reconhecidos como possíveis praguicidas foi feita em coluna capilar com fases e polaridades (SPB ${ }^{\mathrm{TM}} 20$ and $\mathrm{HP}^{\mathrm{TM}}$ 1) e também o sistema de injeção on column.

Alguns dos inseticidas organofosforados polares como 0 acefato, monocrotofós e metamidofós foram analisados utilizando-se o detector de FPD, as condições cromatográficas foram: coluna megabore $30 \mathrm{~m} \times 0,53 \mathrm{~mm}$ de diâmetro interno e $25 \mu \mathrm{m}$ de espessura do filme (DB ${ }^{\mathrm{TM}} 1701$ ); o programa de temperatura empregado foi: $200^{\circ} \mathrm{C} / 10$ minutos, sistema de injeção on column a $220^{\circ} \mathrm{C}$, tempo de espera de 2 minutos, temperatura do detector de: $220^{\circ} \mathrm{C}$; fluxo de gases: gás de arraste (nitrogênio) $5 \mathrm{~mL} /$ minuto e $25 \mathrm{~mL} /$ minuto make up, hidrogênio a 140 $\mathrm{mL} /$ minuto, ar sintético 1:80 $\mathrm{mL} /$ minuto e ar sintético 2:175 $\mathrm{mL} /$ minuto. A confirmação e quantificação de picos reconhecidos como possíveis praguicidas foi feita em coluna megabore com fase de polaridade $\left(\mathrm{DB}^{\mathrm{TM}} 5\right)$. Também foi utilizado sistema de injeção on column.

Para o cálculo da quantidade de praguicida encontrado na amostra analisada (R) foi utilizada a seguinte fórmula:

$$
\mathrm{R}=\frac{\text { área da amostra } \times \text { concentração do padrão }}{\text { área do padrão } \times \text { massa da amostra }} \times \mathrm{F}
$$

Onde:

$\mathrm{R}$ é dado em $\mathrm{mg}$ de ingrediente ativo/kg de amostra e $\mathrm{F}$ pela seguinte fórmula: 


$$
F=\frac{V 1 \times V 2 \times V 3 \times V 4}{V 5 \times V 6 \times V 7}
$$

Sendo:

$\mathrm{V} 1$ = volume final - eluato

V2 = volume de água e acetona - extração

V3 = volume da solução para injeção no GPC

V4 = volume de solução após o GPC e secagem da amostra

$\mathrm{V} 5$ = volume recolhido na etapa de ext

V6 = volume injetado no GPC (loop)

V7 = volume recolhido para a etapa de purificação com sílica gel

\subsubsection{Estudos de recuperação}

Os estudos de recuperação correspondem à avaliação da metodologia analítica empregada. Para estes estudos uma quantidade do praguicida a ser analisado é adicionada à amostra de ensaio, podendo ser de 10 a $50 \mu \mathrm{L}$. A amostra para os estudos de recuperação deve ser oriunda de uma testemunha ou uma amostra negativa e após a adição do praguicida é esperado um tempo de pelo menos 10 minutos para iniciar a extração; desta forma, o sistema pode entrar em equilíbrio favorecendo a análise para a avaliação do praguicida. Nos estudos de recuperação foram incluídos os praguicidas para os quais a legislação brasileira e o Codex Alimentarius estabeleceram LMRs. Para atender a legislação brasileira, apenas a etiona teve seu estudo realizado, uma vez que o 2,4D, a ciromasina e o 
tiadiazuron não são possíveis de serem analisados por metodologia multirresíduos e para atender a legislação internacional, outros praguicidas foram estudados inclusive os organoclorados, vale ressaltar que, para muitos praguicidas o Codex Alimentarius estabeleceu o LMR no Limite de Quantificação (LOQ) ou "próximo de", isto é, para alguns dos praguicidas não há estudos para estabelecimento de limite então utilizase um valor teórico. As amostras de ovo foram fortificadas com os padrões de praguicidas em dois níveis diferentes, tendo como referência os LMRs estabelecidos para cada praguicida, podendo ter sido utilizado o próprio ou o equivalente onde a metodologia responde adequadamente. Todos os estudos de recuperação foram realizados em triplicata.

A porcentagem de recuperação entre $70-120 \%$ para as concentrações estudadas foi considerada adequada para a maioria dos praguicidas (CODEX ALIMENTARIUS, 2008).

Os praguicidas escolhidos para os estudos de recuperação em ovo foram: Acefato, Alacloro, Aldrim, Bifentrina, Carbaril, Cipermetrina, Clorpirifós, op'DDD, pp'DDD, op'DDE, pp'DDE, op'DDT, pp'DDT, Deltametrina, Demetom-S-metil sulfóxido, Diazinona, Dicofol, Dimetoato, Dieldrim, Disulfotom, Alfa endossulfam, Beta endossulfam, Endossulfam sulfato, Endrim, Etiona, Fenpropatrina, Fentoato, Fenvalerato, Forato, Heptacloro, trans heptacloro epóxi, Alfa $\mathrm{HCH}$, Beta $\mathrm{HCH}$, Gama $\mathrm{HCH}$, Metamidofós, Metidationa, Monocrotofós, Permetrina, Pirimifós metil, Profenofós, Propiconazol, Quintozene, triadimenol e Vinclozolina. Além dos praguicidas citados anteriormente e devido à utilização de método multirresíduos, as amostras foram avaliadas para outros produtos como: Aldicarbe, Aldicarbe sulfona, Alfa cipermetrina, Ametrina, Amitraz, Atrazina, Azinfós etil, Benalaxil, Benomil, Beta ciflutrina, Bromopropilato, Captafol, Captana, Carbofenotiom, Carbofurano, 
Carbosulfano, 3-hidroxi carbofurano, ciazofamide, Ciflutrina, Cimoxanil, Ciproconazol, Cis permetrina, Clorfenvinfós, Clorfluzurom, Clorobenzilato, Clorotalonil, Demetom-S-metil e metabólitos (sulfona e sulfóxido), Diclorvós, Dicrotofós, Difenoconazol, Dimetenamida, Dimetenamida-P, Dodecacloro, Epoxiconazol, Espirodiclofeno, Etofenproxi, Fenarimol, Fenitrotiona, Fenotiol, Fensulfotiona, Fentiona, Flazasulfurom, fluazinam, flutriafol, Folpete, Formotiona, Fosalona, Fosmete, HCB, Imazalil, Imidaclorprido, Iprodiona, Lactofen, Lambda cialotrina, Malaoxona, Malationa, Metalaxil, Metiocarbe, Metomil, Mevinfós, Nalede, Nicosulfurom, Novaluron, Ometoato, Paraoxona etílica, Paraoxona metílica, Parationa etílica, Parationa metílica, Petoxamide, Piridafentiona, Proazoltiom, Procimidone, Procloraz, Prometrina, Propargite, Propoxur, Simazina, Tebuconazol, Terbutilazina, Tetraconazol, Tetradifom, Tiabendazol, Tiometom, Trans permetrina, Triadimefom, Triazofós, Triclofom, Vamidotiom e Vinclozolina. Porém, foi estabelecido que os estudos de recuperação para estes outros praguicidas seriam realizados quando as amostras apresentassem resultados positivos e neste caso elas seriam analisadas novamente.

Muitos dos praguicidas com LMR estabelecido pelo Codex Alimentarius não são possíveis de se analisar por método multirresíduos e, desta forma, não constam da lista. Para os praguicidas com valores de LMR próximos aos Limites de Quantificação (LOQ) foram escolhidos os melhores resultados analíticos para os estudos de recuperação.

Como critério para a avaliação dos níveis de resíduos encontrados nas amostras utilizou-se como limite de quantificação (LOQ) o menor valor de um resíduo que pode ser identificado e calculado na metodologia analítica escolhida. Existem referências que estabelecem o LOQ como 5, 6 ou 10 vezes o desvio padrão 
dos resultados das recuperações no menor valor de concentração ou desvio padrão do resultado da amostra testemunha (IUPAC, 2002) 
RESULTADOS 


\section{RESULTADOS}

A Tabela 3 mostra os LMR estabelecidos pela legislação brasileira e pelo Codex Alimentarius, os estudos de fortificação de praguicidas em amostras de ovo e o limite de quantificação.

Os limites de quantificação para os praguicidas pesquisados em amostras de ovo variaram de $0,003 \mathrm{mg} / \mathrm{kg}$ a $0,150 \mathrm{mg} / \mathrm{kg}$ (forato) e estes atendem as necessidades para pesquisas de resíduos, seguindo orientação dos LMR estabelecidos pela legislação brasileira e Codex Alimentarius.

Os praguicidas organoclorados foram os que apresentaram os menores limites de quantificação, como os isômeros do DDT e $\mathrm{HCH}$, bem como alguns piretróides, como cipermetrina, fenpropatrin e fenvarelato.

O organofosforado etion, que possui LMR estabelecido no Brasil, foi o praguicida que apresentou maior número de variações nos estudos de fortificação, sendo que este resultado é esperado para este composto segundo a metodologia estudada (THEIR, 1992 MODULAR MULTIPLE REVISED VERSION OF THE DFG METHOD S19, 1999).

Dos praguicidas estudados, o herbicida alacloro foi encontrado em uma amostra na quantidade de $0,01 \mathrm{mg} / \mathrm{kg}$. 
Tabela 3 - Estudos de fortificação de praguicidas

(continua)

\begin{tabular}{|c|c|c|c|c|c|c|}
\hline \multirow{2}{*}{ Praguicida } & \multirow{2}{*}{ LMR BR ${ }^{1}$} & \multirow{2}{*}{ LMR C $d^{2}$} & \multicolumn{2}{|c|}{ Estudo de Fortificação } & \multirow{2}{*}{ DP } & \multirow{2}{*}{$L^{5}$} \\
\hline & & & Nível $^{3}$ & $\mathrm{MR}^{4}$ & & \\
\hline \multirow{2}{*}{ acefato } & \multirow{2}{*}{0} & \multirow{2}{*}{0,1} & 0,10 & 63,3 & 11,547 & \multirow{2}{*}{0,08} \\
\hline & & & 1,00 & 63,8 & 11,848 & \\
\hline \multirow{4}{*}{ alacloro } & \multirow{4}{*}{0} & \multirow{4}{*}{0} & 0,01 & 96,7 & 25,166 & \multirow{4}{*}{0,003} \\
\hline & & & 0,02 & 80,8 & 17,746 & \\
\hline & & & 0,10 & 67,3 & 6,393 & \\
\hline & & & 0,20 & 114 & 38,911 & \\
\hline \multirow{2}{*}{ aldrin } & \multirow{2}{*}{0} & \multirow{2}{*}{0,1} & 0,02 & 77,9 & 9,432 & \multirow{2}{*}{0,006} \\
\hline & & & 0,10 & 90,9 & 1,414 & \\
\hline \multirow{2}{*}{ bifentrina } & \multirow{2}{*}{0} & \multirow{2}{*}{0,01} & 0,01 & 106,7 & 11,547 & \multirow{2}{*}{0,003} \\
\hline & & & 0,10 & 75,7 & 15,044 & \\
\hline \multirow{2}{*}{ carbaril } & \multirow{2}{*}{0,5} & \multirow{2}{*}{0} & 0,25 & 86,7 & 0,075 & \multirow{2}{*}{0,06} \\
\hline & & & 0,50 & 119,9 & 8,437 & \\
\hline \multirow{2}{*}{ cipermetrina } & \multirow{2}{*}{0} & \multirow{2}{*}{0,05} & 0,01 & 92,8 & 21,714 & \multirow{2}{*}{0,003} \\
\hline & & & 0,10 & 119,7 & 9,604 & \\
\hline clornirifós & 0 & 001 & 0,05 & 94,4 & 13,684 & 0015 \\
\hline & & & 0,10 & 80,6 & 13,919 & \\
\hline 6مמח'מת & 0 & 01 & 0,01 & 80,7 & 21,501 & 0003 \\
\hline & & & 0,10 & 64,0 & 6,245 & \\
\hline 6חمמ'nn & 0 & 01 & 0,01 & 81,3 & 15,275 & 0003 \\
\hline & & & 0,10 & 63,7 & 6,646 & \\
\hline 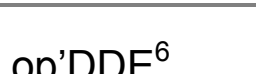 & 0 & 01 & 0,01 & 101,0 & 6,291 & 0003 \\
\hline & & & 0,10 & 104,0 & 6,0 & \\
\hline pp'DDE 6 & 0 & 01 & 0,05 & 91,9 & 20,261 & 0.015 \\
\hline PP БLᄃ & 0 & 0,1 & 0,10 & 93,6 & 3,523 & 0,015 \\
\hline 6"מم' & 0 & 01 & 0,05 & 92,9 & 9,711 & 0015 \\
\hline & & & 0,10 & 92,4 & 19,568 & \\
\hline pp'DDT $^{6}$ & 0 & 0.1 & 0,05 & 81,2 & 6,117 & 0.015 \\
\hline 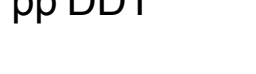 & 0 & 0,1 & 0,10 & 81,2 & 10,238 & 0,015 \\
\hline deltametrina & 0 & 002 & 0,02 & 90,9 & 7,537 & 0006 \\
\hline & & & 0,20 & 94,8 & 6,008 & \\
\hline
\end{tabular}


(continuação)

\begin{tabular}{|c|c|c|c|c|c|c|}
\hline \multirow{2}{*}{ Praguicida } & \multirow{2}{*}{ LMR BR $^{1}$} & \multirow{2}{*}{ LMR $C^{2}{ }^{2}$} & \multicolumn{2}{|c|}{ Estudo de Fortificação } & \multirow{2}{*}{ DP } & \multirow{2}{*}{$L Q^{5}$} \\
\hline & & & Nível $^{3}$ & $\mathbf{M R}^{4}$ & & \\
\hline \multirow{3}{*}{$\begin{array}{l}\text { demeton-S- } \\
\text { metil } \\
\text { sulfóxido }\end{array}$} & \multirow{3}{*}{0} & \multirow{3}{*}{0,05} & 0,05 & 82,3 & 6,204 & \multirow{3}{*}{0,015} \\
\hline & & & & & & \\
\hline & & & 0,10 & 90,2 & 4,725 & \\
\hline \multirow{2}{*}{ diazinon } & \multirow{2}{*}{0} & \multirow{2}{*}{0} & 0,02 & 100,5 & & \multirow{2}{*}{0,006} \\
\hline & & & 0,20 & 100,8 & 16,266 & \\
\hline \multirow{2}{*}{ dicofol } & \multirow{2}{*}{0} & \multirow{2}{*}{0,05} & 0,05 & 92,5 & 17,50 & \multirow{2}{*}{0,015} \\
\hline & & & 0,10 & 112,9 & 8,350 & \\
\hline \multirow{2}{*}{ dieldrin } & \multirow{2}{*}{0} & \multirow{2}{*}{0,10} & 0,05 & 93,4 & 23,878 & \multirow{2}{*}{0,015} \\
\hline & & & 0,10 & 84,7 & 12,017 & \\
\hline \multirow{2}{*}{ dimetoato } & \multirow{2}{*}{0} & \multirow{2}{*}{0,05} & 0,05 & 114,3 & 10,693 & \multirow{2}{*}{0,015} \\
\hline & & & 0,10 & 114,0 & 14,177 & \\
\hline \multirow{2}{*}{ disulfoton } & \multirow{2}{*}{0} & \multirow{2}{*}{0,02} & 0,02 & 70,9 & 1,389 & \multirow{2}{*}{0,006} \\
\hline & & & 0,2 & 71,3 & 1,040 & \\
\hline alfa & 0 & 0 & 0,04 & 95,5 & 9,669 & 0010 \\
\hline endosulfan & U & U & 0,10 & 91,9 & 3,671 & 0,012 \\
\hline beta & 0 & 0 & 0,04 & 81,8 & 12,662 & 012 \\
\hline endosulfan & 0 & 0 & 0,10 & 78,3 & 1,258 & 0,012 \\
\hline endosulfan & 0 & 0 & 0,04 & 112,2 & 10,774 & 0,012 \\
\hline sulfato & & & 0,10 & 73,7 & 1,041 & 0,012 \\
\hline endrin & 0 & 0 & 0,05 & 97,6 & 10,887 & 0015 \\
\hline (1) & 0 & 0 & 0,10 & 81,9 & 3,671 & ט, \\
\hline etion & 020 & 0 & 0,20 & 75,0 & 33,151 & 006 \\
\hline Etivin & $0, \angle U$ & 0 & 0,40 & 57,6 & 0,173 & 0,00 \\
\hline fonnronatrin & 0 & 01 & 0,01 & 106,9 & 7,611 & $0 \cap 03$ \\
\hline Iепрторайіп & 0 & 0,01 & 0,10 & 90,3 & 10,017 & 0,003 \\
\hline fontonto & 0 & 005 & 0,10 & 109,3 & 44,736 & 003 \\
\hline & & & 0,25 & 87,3 & 24,030 & \\
\hline fenvalerato & 0 & 0 & 0,01 & 120,6 & 1,858 & ( \\
\hline & & & 0,02 & 119,8 & 6,022 & \\
\hline
\end{tabular}


(continuação)

\begin{tabular}{|c|c|c|c|c|c|c|}
\hline \multirow{2}{*}{ Praguicida } & \multirow{2}{*}{$\mathrm{LMR}_{\mathrm{BR}}{ }^{1}$} & \multirow{2}{*}{ LMR Cd ${ }^{2}$} & \multicolumn{2}{|c|}{ Estudo de Fortificação } & \multirow{2}{*}{ DP } & \multirow{2}{*}{$\mathrm{LQ}^{5}$} \\
\hline & & & $\mathrm{Nível}^{3}$ & $\mathrm{MR}^{4}$ & & \\
\hline \multirow{2}{*}{ forate } & \multirow{2}{*}{0} & \multirow{2}{*}{0,05} & 0,50 & 69,3 & 0,974 & \multirow{2}{*}{0,15} \\
\hline & & & 1,00 & 69,2 & 0,764 & \\
\hline \multirow{2}{*}{ heptacloro } & \multirow{2}{*}{0} & \multirow{2}{*}{0,05} & 0,02 & 85,8 & 13,788 & \multirow{2}{*}{0,006} \\
\hline & & & 0,10 & 99,7 & 24,072 & \\
\hline \multirow{3}{*}{$\begin{array}{l}\text { Trans } \\
\text { heptacloro } \\
\text { epóxi }\end{array}$} & \multirow{3}{*}{0} & \multirow{3}{*}{0} & 0,02 & 87,2 & 11,615 & \multirow{3}{*}{0,006} \\
\hline & & & & & & \\
\hline & & & 0,10 & 88,4 & 1,644 & \\
\hline \multirow{2}{*}{ alfa $\mathrm{HCH}$} & \multirow{2}{*}{0} & \multirow{2}{*}{0} & 0,01 & 90,7 & 21,605 & \multirow{2}{*}{0,003} \\
\hline & & & 0,05 & 104,7 & 12,421 & \\
\hline \multirow{2}{*}{ beta $\mathrm{HCH}$} & \multirow{2}{*}{0} & \multirow{2}{*}{0} & 0,01 & 77,5 & 3,106 & \multirow{2}{*}{0,003} \\
\hline & & & 0,05 & 116,8 & 14,752 & \\
\hline \multirow{2}{*}{ gama $\mathrm{HCH}$} & \multirow{2}{*}{0} & \multirow{2}{*}{0,01} & 0,01 & 94,4 & 26,836 & \multirow{2}{*}{0,003} \\
\hline & & & 0,05 & 92,1 & 11,207 & \\
\hline motamidnfóc & 0 & 001 & 0,10 & 58,3 & 7,837 & 003 \\
\hline . metaminuovos & 0 & 0,01 & 0,25 & 60,0 & 5,0 & 0,00 \\
\hline motidation & 0 & (00? & 0,01 & 105,2 & 1,757 & 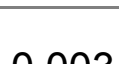 \\
\hline meturationta & 0 & 0,02 & 0,02 & 111,2 & 7,787 & 0,000 \\
\hline monongotafó & 0 & 0 & 0,10 & 62,0 & 10,817 & ב0 0 \\
\hline 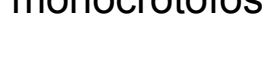 & 0 & 0 & 1,0 & 100,3 & 21,502 & 0,00 \\
\hline normotring & 0 & 010 & 0,10 & 80,3 & 5,507 & \\
\hline 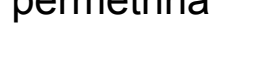 & 0 & 0,10 & 0,20 & 88,3 & 40,414 & 0,00 \\
\hline nirimifós motil & 0 & 005 & 0,05 & 78,3 & 22,133 & 015 \\
\hline pirmonus metim & 0 & 0,00 & 0,10 & 90,4 & 33,873 & 0,010 \\
\hline nurfonofó & 0 & ר0? & 0,10 & 86,3 & 37,287 & ב0 0 \\
\hline pitivios & 0 & 0,02 & 0,50 & 101,0 & 20,518 & 0,00 \\
\hline pronisonozolo & 0 & 05 & 0,10 & 93,8 & 0,865 & 20 \\
\hline piopiconiazuie & 0 & 0,00 & 0,25 & 97,7 & 2,238 & 0,00 \\
\hline Muintoron & 0 & 20 & 0,01 & 78,3 & 18,770 & בח \\
\hline & & & 0,10 & 68,6 & 6,626 & \\
\hline
\end{tabular}


(conclusão)

\begin{tabular}{|c|c|c|c|c|c|c|}
\hline \multirow{2}{*}{ Praguicida } & \multirow{2}{*}{ LMR BR $^{1}$} & \multirow{2}{*}{ LMR $C d^{2}$} & \multicolumn{2}{|c|}{ Estudo de Fortificação } & \multirow{2}{*}{ DP } & \multirow{2}{*}{$\mathbf{L Q}^{5}$} \\
\hline & & & Nível $^{3}$ & $\mathrm{MR}^{4}$ & & \\
\hline \multirow{2}{*}{ triadimenol } & \multirow{2}{*}{0} & \multirow{2}{*}{0,05} & 0,10 & 40,3 & 19,804 & \multirow{2}{*}{0,075} \\
\hline & & & 0,25 & 73,9 & 15,373 & \\
\hline \multirow{2}{*}{ vinclozolina } & \multirow{2}{*}{0} & \multirow{2}{*}{0,05} & 0,10 & 100,0 & 14,434 & \multirow{2}{*}{0,075} \\
\hline & & & 0,25 & 72,3 & 1,412 & \\
\hline
\end{tabular}

${ }^{1}$ Limite Máximo de Resíduo estabelecido pela legislação brasileira, $\mathrm{mg} / \mathrm{kg}$

${ }^{2}$ Limite Máximo de Resíduo estabelecido pelo Codex Alimentarius, $\mathrm{mg} / \mathrm{kg}$

${ }^{3}$ Nível de fortificação, $\mathrm{mg} / \mathrm{kg}$

${ }_{5}^{4}$ Média de recuperação, \%

${ }^{5}$ Limite de quantificação, $\mathrm{mg} / \mathrm{kg}$

${ }^{6}$ DDT e isômeros 
DISCUSSÃO 


\section{DISCUSSÃO}

Os estudos de recuperação mostraram que a metodologia analítica escolhida para a análise de resíduos de praguicidas em amostras de ovo foi bastante eficiente. O método escolhido também foi utilizado por Scharenberg et al. (1997) na Alemanha para avaliar a presença de praguicidas em aves aquáticas. Sabe-se que as metodologias analíticas empregadas para a avaliação de resíduos de praguicidas em matrizes, nas quais o teor de gordura é elevado, apresentam certa dificuldade na purificação da amostra sem que ocorra a perda das substâncias de interesse. A presença de gordura também dificulta a análise dos compostos apolares como os organoclorados devido a sua afinidade a esta fase. Para os compostos organofosforados e halogenados, a matriz ovo, tem uma grande quantidade de coextrativos havendo assim a possibilidade de, durante a quantificação por cromatografia gasosa, o resultado encontrado ser muito além do esperado. Este fato é considerado efeito matriz e pode ser explicado devido a uma interferência na degradação/adsorção térmica que ocorre no sistema dada à presença de coextrativos que bloqueiam esta atividade e permitem assim um aumento na quantidade do analito analisado.

Comparando com trabalhos realizados por outros pesquisadores (WIGFIELD et al., 1996; JUHLER, 1997; SCHARENBERG; EBEDLING, 1998, FURUSAWA et al., 1998, FIDDLER et al., 1999; SCHENCK; DONOGHUE, 2000; SZERLITICS et al., 2000), que utilizaram o mesmo procedimento empregado neste trabalho, isto é, além da análise convencional de extração feita com solvente orgânico, partição líquido/líquido e purificação com GPC e sílica gel ou florisil, o emprego de extração em fase sólida, os resultados mostraram-se semelhantes para a análise de ovo. 
Outros autores analisaram amostras de ovo, principalmente para praguicidas organoclorados e obtiveram resultados no intervalo considerado adequado para análise multirresíduos (HILL, 1990; MOURER et al., 1990,).

Os limites de quantificação para os praguicidas estiveram em torno de 0,003 $\mathrm{mg} / \mathrm{kg}$ a $0,030 \mathrm{mg} / \mathrm{kg}$. Os praguicidas organoclorados foram os que apresentaram os menores limites de quantificação devido a sua estabilidade e características físicoquímicas, ao passo que os organofosforados, como a etiona, que possui LMR estabelecido no Brasil, apresentou variações em seus resultados.

O praguicida alacloro foi encontrado em uma das amostras analisadas em uma quantidade de $0,01 \mathrm{mg} / \mathrm{kg}$. A presença deste composto pode estar relacionada à dieta alimentar das aves e também as características físico-químicas deste herbicida que pode estar relacionada à presença de cloro em sua molécula, conferindo maior estabilidade ao praguicida, podendo desta forma ser identificado nos tecidos de reserva dos animais, como o ovo. O alacloro é classificado como um praguicida pouco persistente, 1 a 12 semanas no solo, sendo biodegradado por microorganismos, porém a presença em alimentos como o milho está associado ao uso agrícola (colheita antes da maturação ou em tratamento pós-emergentes) (MÍDIO; MARTINS, 1997).

Alguns trabalhos relatam que em estudos nos quais um praguicida é adicionado na alimentação animal, em geral, pode haver uma transferência em torno de 0,1 a $1,0 \%$ dele para o ovo. A transferência de praguicidas ocorre tanto para produtos polares quanto aqueles apolares, podendo ficar armazenados nos ovos (DONOGHUE et al., 1995; DONOGHUE et al., 1996; DONOGHUE et al., 1997; SCHENCK; DONOGHUE, 2000; SZERLETICS, et al., 2000). Outros autores também descrevem a transferência de praguicidas em relação à ingestão de alimentos 
contaminados, à ração animal proveniente de restos de animais e ao período de exposição (KAN; TUNISTRA, 1976; ARGOTE-RIVERO et al., 1988, MUGAMBI et al., 1989, NOBLE et al., 1990, EL AHRAF, et al. 1990 e BENNETT et al., 1991).

Na Polônia, Niewiadowska et al. (1996) analisaram 220 amostras de ovos de galinhas criadas no sistema intensivo (em granjas) de alimentação e 235 amostras de ovos de galinhas criadas no sistema convencional (extensivo). Neste estudo feito em 1994, os autores observaram que todas as amostras de ovos apresentaram contaminação por DDT e seus metabólitos; as concentrações encontradas nos ovos das aves criadas no sistema convencional foram 5 vezes maiores do que aquelas no sistema intensivo, $0,53 \mathrm{mg} / \mathrm{kg}$ de gordura e $0,10 \mathrm{mg} / \mathrm{kg}$ de gordura respectivamente. Os valores encontrados para o DDT e metabólitos excederam os LMR recomendados pelo país. Outros praguicidas como o $\mathrm{HCB}$ e o $\mathrm{HCH}$ também foram encontrados nas amostras e apresentaram a mesma diferença na concentração, quando comparados os dois sistemas, sendo $0,004 \mathrm{mg} / \mathrm{kg}$ de gordura e $0,001 \mathrm{mg} / \mathrm{kg}$ de gordura para o HCB no sistema convencional e intensivo, respectivamente, e $0,011 \mathrm{mg} / \mathrm{kg}$ de gordura para o sistema convencional e $0,006 \mathrm{mg} / \mathrm{kg}$ de gordura para o sistema intensivo de $\mathrm{HCH}$. Os autores sugerem que a dieta alimentar dos animais favorece a presença de contaminantes químicos nos ovos.

Por outro lado, Howe et al. (1996) nos EUA estudaram a alteração na reprodução de passarinhos após a aplicação do praguicida organofosforado malationa utilizado para diminuir a presença de insetos que fazem parte da dieta alimentar destas aves. Os autores não observaram efeitos diretos devido à presença da malationa, apenas uma redução da dieta básica dos animais. 


\subsection{PRAGUICIDAS EM OVO}

No Brasil, poucos trabalhos descrevem estudos de resíduos de praguicidas em alimentos, principalmente aqueles de origem animal como o ovo. Apesar de o ovo ser um alimento bastante consumido pela população, ser um produto de exportação e também ser utilizado na produção de vários alimentos industrializados, pouca atenção é dispensada a este produto. Em estudo realizado junto ao GEMS/FOOD, Barreto et al., em 1992, analisaram 113 amostras de gorduras de aves, sendo encontrados em 1988, 96\% de $\mathrm{HCH}, 84 \%$ de DDT e $56 \%$ de dieldrim. Em 1989 foram encontrados 3\% de $\mathrm{HCB}, 30 \%$ de $\mathrm{HCH}, 50 \%$ de DDT e $8 \%$ de dieldrim; em 1990, 18\% de $\mathrm{HCB}, 18 \%$ de $\mathrm{HCH}, 32 \%$ de DDT e $32 \%$ de dieldrim; e em $1991,43 \%$ de $\mathrm{HCH}$ e $27 \%$ de dieldrim.

Outro trabalho realizado no Brasil usou o ovo como um indicador da presença de praguicidas em uma área tropical, próxima ao Rio de Janeiro, onde se utilizava o DDT para o combate do vetor da malária. Neste trabalho, Vieira et al. (2001) relataram que as coletas dos ovos foram feitas nas áreas onde havia a presença dos vetores e que havia sido utilizado o DDT para o combate. As amostras foram analisadas para praguicidas organoclorados e o maior valor encontrado foi de 1,98 $\mathrm{mg} / \mathrm{kg}$ de DDT. O metabólito DDE foi encontrado em $82 \%$ das amostras analisadas.

Romão et al (2007) na região Sul brasileira estudou a presença dos praguicidas aldicarbe e dimetoato em amostras de ovo e observaram que $30,5 \%$ estavam contaminadas por dimetoato e 5,5\% por aldicarbe; os autores sugerem que esta contaminação dos ovos produzidos na região do Estado do Paraná possa estar associada ao uso de produtos veterinários para o combate de moscas. Contudo, vale destacar que no mercado brasileiro não existe nenhum produto veterinário 
registrado no MAPA que contenha esses praguicidas na sua formulação (COMPÊNDIO DE PRODUTOS VETERINÁRIOS - SINDAN, 2008).

Em outros países da América Latina, os estudos de resíduos de praguicidas em ovos também são escassos. Albert; Rendón-Von-Osten, em 1988, no México, observaram que os praguicidas mais encontrados e com elevados níveis de concentração foram: o heptacloro epóxi em 40\% das amostras, o pp’DDT em 80\% das amostras e o pp'DDE em $100 \%$ das amostras estudadas.

Em Cuba, Argote-Rivero et al., em 1988, analisaram 63 amostras de ovos e os praguicidas organoclorados mais encontrados foram DDT e metabólitos e lindano. Os autores encontraram 0,313 mg/kg de pp'DDT; 0,105 mg/kg de pp'DDE; 0,116 $\mathrm{mg} / \mathrm{kg}$ de pp'DDE; 0,072 mg/kg de op'DDT; 0,028 mg/kg de lindano e 0,567 mg/kg de DDT total. Os autores também relataram que 9,7\% estiveram acima do LMR para DDT e 6,6\% para o lindano.

Em análises realizadas em países do continente asiático, como a Índia, onde o consumo está separado de acordo com a dieta alimentar da população (vegetarianos e não vegetarianos), Singh; Chawla, em 1988, observaram que todos os alimentos analisados apresentaram-se contaminados por DDT e BHC. A quantidade média encontrada para os praguicidas DDT, DDE e $\mathrm{HCH}$ em alimentos de origem animal foi de $0,026 \mathrm{mg} / \mathrm{kg}$ para o op'DDT; 0,095 $\mathrm{mg} / \mathrm{kg}$ para o pp'DDE; 0,107 mg/kg para o pp'DDT e de 0,190 mg/kg para o $\mathrm{HCH}$. Os autores relataram que as maiores concentrações dos praguicidas citados foram encontradas nos alimentos de origem animal. $\mathrm{O}$ uso de praguicidas organoclorados está relacionado principalmente ao baixo custo destes produtos. Kannaru et al., em 1992, realizaram coletas em 4 diferentes regiões na índia, no período de 1984 e observaram que os praguicidas mais freqüentes foram: $\mathrm{HCH}$, DDT, aldrim e dieldrim, $\mathrm{HCB}$ e heptacloro. 
Kannan, et al., (1995), em estudo feito em animais aquáticos, observaram que as ostras e outros gastrópodes expostos aos resíduos de compostos organoestanosos (organometálicos derivados do estanho) apresentaram deformidades. Os autores relataram que a ausência de estudos de monitorização, principalmente, de países em desenvolvimento contribui para a falta de informação a respeito dos resíduos de contaminantes em alimentos; tais estudos revelam a importância da presença destas substâncias nos alimentos e para a saúde do consumidor.

Outros estudos para a verificação de contaminantes em alguns alimentos realizados por Kannan et al. (1997) na Índia, a partir de 1968, mostraram que o DDT e o $\mathrm{HCH}$ foram os produtos mais encontrados e que os cereais e outros grãos que compõem a dieta principal estavam contaminados. Estes praguicidas foram amplamente utilizados para o controle de vetores e, devido à maioria da população consumir a dieta vegetariana, pouca informação existe a respeito de alimentos de origem animal, tais como o ovo; porém, em análises realizadas, a concentração de DDT e $\mathrm{HCH}$ neste alimento foi inferior a $1 \mu \mathrm{g} / \mathrm{g}$ e o mesmo valeu para lindano, aldrim e dieldrim.

$\mathrm{Na}$ China o DDT e o $\mathrm{HCH}$ estavam presentes em amostras de ovo com valores de 6,7 a 24 ng/g para o DDT e de 13 a 72 ng/g para o HCH (LI et al., 1998). Na Indonésia a quantidade de DDT em amostras de ovo foi em torno de $8770 \mathrm{ng} / \mathrm{g}$, excederam em muito os valores estabelecidos pela FAO (resíduos); este praguicida tem sua presença relacionada ao uso também para o controle de vetores. Os autores (INDRANINGSIH et al., 1988) fizeram uma coletânea de trabalhos de estudos de praguicidas realizados em países da Ásia e Oceania. 
Estudos de monitorização de resíduos de praguicidas em ovos realizado na China, no período de 1978 a 1992, Li et al. (1998) relataram que, apesar daquele país junto com Índia, Japão e EUA terem sido os maiores consumidores de inseticidas organoclorados como lindano e DDT, os níveis de contaminação dos ovos tem diminuído desde 1983, coincidindo com o período no qual estes produtos foram banidos na China. Os autores constataram que a presença de resíduos do $\mathrm{HCH}$ e seus isômeros diminuíram cerca de 30 vezes nos ovos.

No Japão, Kuwabara et al. (1997) analisaram 115 diferentes alimentos, divididos em 13 grupos e constataram que peixes, ovos e carnes, bem como leite e derivados foram os principais grupos onde se destacou a presença de praguicidas organoclorados, sendo que foi considerada a principal rota de exposição. A ingestão diária dos organoclorados ficou em torno de 0,56 a 4,77 $\mu$ g para o DDT, 0,05 a 3,65 $\mu \mathrm{g}$ para o $\mathrm{HCH}, 0,18$ a $1,51 \mu \mathrm{g}$ para o clordano, até $0,17 \mu \mathrm{g}$ para o heptacloro, até $0,90 \mu \mathrm{g}$ para o HCB e até $0,49 \mu \mathrm{g}$ para o dieldrim. Todos os valores de ingestão foram considerados abaixo da ingestão diária aceitável de acordo com a legislação japonesa e nas amostras de ovos os valores encontrados estiveram abaixo dos LMR estabelecidos pela Organização Mundial de Saúde.

No continente africano, Mugambi et al. (1989), no Quênia, relataram que em um total de 367 amostras de ovos coletadas em 61 fazendas, criadas no sistema intensivo, no distrito do Quênia no período de 1984, foram encontrados resíduos de 10 praguicidas organoclorados, sendo eles o DDE em $100 \%$ das amostras, o DDT em $98 \%$, o dieldrim em $95 \%$, o lindano em $66 \%$, o DDD em $46 \%$, o op'DDT em $17 \%$, o beta $\mathrm{HCH}$ em $9 \%$, o alfa $\mathrm{HCH}$ em $5 \%$, o endrim em $4 \%$ e o aldrim em $0,5 \%$. Os autores também observaram que os ovos das aves criadas livres, próximas a 
plantações de arroz tiveram todas as amostras positivas para os organoclorados estudados, demonstrando a existência de contaminação do meio ambiente.

Kahunyo et al., em 1988, analisaram 105 amostras de ovos, coletadas em 7 regiões no Quênia, observaram que $17,1 \%$ das amostras apresentaram níveis elevados de DDT, estando os valores acima do LMR do país.

Kessabi et al., em 1990, no Marrocos relataram que no estudo de monitorização realizado naquele país, os praguicidas organoclorados foram os mais encontrados, sendo que $86 \%$ apresentaram resíduos de lindano e $93 \%$ com resíduos de hexaclorobenzeno, e $7,5 \%$ os valores encontrados ultrapassaram o LMR.

Woktelius e Edwards (1997) em estudo realizado com diferentes espécies de aves observaram que os praguicidas organoclorados são os produtos mais freqüentes, principalmente, o DDT e o dieldrim.

El-Hoshi e Nazem (2000), no Egito, analisaram 40 amostras de ovos desidratados e 10 amostras de albúmen, para os praguicidas organoclorados e organofosforados, e observaram que nas gemas dos ovos desidratados estavam presentes praguicidas organoclorados, sendo: $17,5 \%$ de DDT; $22,5 \%$ de $\mathrm{HCH}$; $12,5 \%$ de heptacloro e $10,0 \%$ de heptacloro epóxi; $12,5 \%$ de dieldrim e $10 \%$ de endrim; estas substâncias não foram encontrados na clara, devido a baixa solubilidade e os praguicidas organofosforados não foram encontrados em nenhuma das amostras analisadas. Todas as amostras que apresentaram organoclorados os valores obtidos estiveram abaixo dos LMR estabelecidos pela legislação.

Na Austrália, Noble (1990) encontrou aldrim e dieldrim em ovo na quantidade de $0,10 \mathrm{mg} / \mathrm{kg}$, sendo que o valor $0,015 \mathrm{mg} / \mathrm{kg}$ é o indicado pela legislação do país; 
para os outros organoclorados o autor não citou valores de limites máximos de resíduos.

Na Indonésia, Indraningsih, et al., em 1988, analisaram 78 amostras de ovos de aves (galinha, codornas e patas). Resíduos de praguicidas organoclorados como lindano, aldrim, dieldrim e DDT e seus metabólitos foram comumente encontrados. Foram comparados os resultados dos ovos de galinha (total de 20 amostras) com ovos de outras aves, como a codorna, e o inseticida organoclorado DDT foi o que esteve mais presente nos ovos analisados, principalmente nos ovos de galinhas, sendo que os níveis encontrados foram mais elevados.

Países do continente americano e europeu possuem programas de monitorização e seus resultados também relatam a contaminação por praguicidas em produtos de origem animal como os ovos.

The KAN-DO team (1995) nos EUA, em estudo de monitorização realizado em 10 anos (1982 a 1991) em alimentos in natura e processados, totalizando 17.050 amostras, observaram que: a) em ovos fritos, o DDE esteve presente em 13 amostras, o demetom-S-metílico sulfona em 2 amostras, o dieldrim em 3 amostras, o heptacloro epóxido em 1 amostra, o trans nanocloro em 1 amostra e os PCBs em 6 amostras; b) para ovos fritos, o DDE esteve presente em 11 amostras, o demetomS-metílico sulfona em 2 amostras, o dieldrim em 1 amostra, o difenil etil fosfato em 1 amostra, o heptacloro epóxido em 1 amostra, o HCB em 5 amostras, o lindano em 1 amostra, a malationa em 2 amostras e o triclorobenzeno em 1 amostra; e c) em ovos cozidos foram encontrados o clordano em 1 amostra, o clorpirifós em 1 amostra, o DDE em 8 amostras, o demetom-S-metil sulfona em 1 amostra, o dieldrim em 6 amostras, o heptacloro epóxido em 1 amostra, o HCB em 1 amostra, o nanocloro em 1 amostra e os PCBs em 2 amostras. 
No Canadá, Frank et al., em 1990 demonstraram que os praguicidas organoclorados diminuíram nos últimos 20 anos após a proibição do uso no país. Neste estudo foram coletadas 602 amostras de produtos de origem animal, sendo 62 amostras de ovo e os resultados foram $21 \%$ das amostras com resíduos de DDE e 14\% com resíduos de lindano.

Durante o período de 1993 a 1995, em projeto de monitorização realizado na Itália, Binato et al. (1996) analisaram 798 amostras para praguicidas organoclorados e 458 para praguicidas organofosforados. Praguicidas organoclorados e organofosforados estiveram presentes em 4,0\% das amostras de ovo analisadas, entre os praguicidas mais encontrados destaca-se o DDT e seus metabólitos e o $\mathrm{HCH}$ e isômeros. A concentração dos produtos encontrados esteve abaixo do LMR permitido.

Na Dinamarca, no período de janeiro de 1995 a dezembro de 1996 foram analisadas 1567 amostras de produtos de origem animal, entre eles ovos de galinha; os autores verificaram a presença de praguicidas organoclorados na maioria das amostras de alimento de origem animal, como ovos e leite (JUHLER et al., 1999).

Zmudzki et al. (1992) no período de 1989 a 1990, na Polônia, analisaram 23 amostras de ovos e constataram a presença de praguicidas organoclorados em todas as amostras analisadas.

$\mathrm{Na}$ Alemanha, Ueberschar (1995) também analisou amostras de ovos e constatou a presença de organoclorados, porém estas substâncias químicas estivam abaixo dos níveis considerados como de risco a saúde.

Darmerud et al. (2007), na Suécia, avaliaram a cesta básica e diferentes produtos consumidos pela população. Destes, os peixes foram os que apresentaram 
as maiores quantidades de resíduos de pesticidas; os autores observaram que a população esteve exposta ao consumo de poluentes orgânicos persistentes.

Os trabalhos acima citados mostraram que os praguicidas organoclorados são aqueles mais encontrados nas amostras analisadas, com uma tendência de declínio, em função da restrição mundial de sua utilização na agropecuária. No presente estudo, foi encontrado apenas em uma única amostra o herbicida alacloro, refletindo também aqui no Brasil a importância da proibição do uso dos praguicidas organoclorados.

\subsection{PRAGUICIDAS, MEIO AMBIENTE E OUTRAS AVES}

Estudos realizados com outras espécies de aves, como aves marinhas demonstram a existência de contaminação no meio ambiente, assim como nos produtos utilizados como alimentação destes animais.

A presença de contaminantes, principalmente praguicidas organoclorados nos ovos pode ser avaliada a partir de estudos de monitorização de diferentes regiões, de diferentes colônias, de diferentes pássaros etc. Turle et al. (1992), nos EUA, validaram um estudo, no qual é sugerida a composição de amostras de ovos de vários ninhos. Os ovos avaliados separadamente e na amostra composta revelaram a presença de contaminantes orgânicos. Os autores não observaram diferenças nos resultados quando comparados àqueles das amostras simples e das compostas.

As aves podem ser utilizadas como indicadores de contaminação do ambiente, principalmente para praguicidas organoclorados, PCBs e metais pesados. Neste sentido, vários autores relataram a presença de contaminantes 
organoclorados em ovos, além de plasma e alimentos que compõe a dieta alimentar destes animais.

Em estudo realizado na Alemanha, em estuários do rio Sena, Vilaine, Loire e Baia de Aiguillon, na França, e em estuários em Portugal, Dietrich et al. (1997) observaram que havia uma relação entre a dieta alimentar e a contaminação dos ovos. Neste trabalho pode-se observar que a distribuição dos contaminantes na costa européia foi desigual. Em 1991 e 1992 vinte ovos de 40 aves (20 casais) foram coletados dos ninhos; repetiram-se as coletas em 1992 e também analisaram os alimentos desses animais (poliquetos, crustáceos, moluscos e larvas de quironomidas). Os ovos mostraram baixa contaminação por organoclorados, porém, os valores encontrados estavam em desacordo com a legislação da Alemanha. Os resultados encontrados foram: 0,7 ppb de alfa $\mathrm{HCH} ; 9,0$ ppb de gama $\mathrm{HCH} ; 7,5$ ppb de HCB e 126,8 ppb de DDT.

Elliott et al. (1994) avaliaram ovos de aves de rapina no período de 1986 a 1989 em Ontário, Canadá, e detectaram a presença de praguicidas organoclorados entre eles o DDE, o DDT, o DDD, dieldrim, heptacloro epóxi, HCB, mirex, oxiclordane, PCBs, cis e trans nanocloro etc. Os pesquisadores, porém, não observaram diferença na espessura da casca dos ovos devido a presença destes poluentes.

Indraningsih et al. (1988), na Indonésia, analisaram um total de 78 ovos de aves (galinhas, codornas, patas etc.) do comércio local e 38 ovos de aves selvagens para presença de praguicidas organoclorados. Os autores observaram a presença de gama $\mathrm{HCH}$, aldrim, dieldrim e DDT em todos os ovos das aves estudadas, sendo que o DDT foi encontrado em maior concentração nos ovos de galinhas (75,94 ppb). Embora os resultados fossem positivos para os praguicidas estudados, os valores 
estavam dentro daqueles estabelecidos pela OMS e, provavelmente, estejam relacionados à presença desses compostos no meio ambiente.

Ormerod et al. (1994), na Irlanda, avaliaram ovos de aves aquáticas para monitorar a presença de praguicidas organoclorados. Os ovos de mergulhão coletados no período de 1988 a 1992 apresentaram os contaminantes HCB e gama $\mathrm{HCH}$. Os autores sugerem que a diferença na presença e concentração destes produtos durante o período estudado esteve relacionada a contaminação do local e a dieta alimentar.

Scharenberg et al. (1998) avaliaram ovos de aves aquáticas no lago Berlau, na Alemanha, e constataram que os ovos apresentaram contaminação por organoclorados, porém em baixa concentração. Os autores relataram que a contaminação dos ovos está relacionada a alimentação das aves e este tipo de trabalho de monitorização serve de indicador da contaminação do lago.

Barret et al. (1996), na Noruega, avaliaram a presença de praguicidas organoclorados em 10 espécies de aves marinhas. Os autores observaram uma diminuição nos níveis de pp'DDE, $\mathrm{HCB}$, beta $\mathrm{HCH}$, gama $\mathrm{HCH}$ e oxiclordano, quando comparados os resultados com aqueles obtidos em 1983.

O'halloran et.al. (1993), na Irlanda, observaram que dos 17 ovos coletados em 1988 e 38 ovos coletados em 1992, o DDT esteve presente em $70 \%$ dos ovos e o DDE foi o praguicida mais encontrado em concentrações de 0,68 mg/kg a 320 $\mathrm{mg} / \mathrm{kg}$. O HCB foi encontrado em apenas uma amostra de ovo em 1988 e em 30\% dos ovos em 1992.

Luke et al. (1989), na Antártica, entre o período de 1978 a 1983, analisaram ovos de 15 diferentes espécies de aves para praguicidas organoclorados, PCBs e mercúrio. As concentrações variaram ntre as diferentes espécies de aves e em 
pingüins da espécie Adelia pingüins, foi encontrado 0,01 $\mu \mathrm{g} / \mathrm{g}$ de HCB e DDE, 0,005 $\mu \mathrm{g} / \mathrm{g}$. A presença destas substâncias foi mais evidente em aves que migraram para diferentes regiões da Antártica.

Pellantova et al. (1989), na Tchecoslováquia, estudaram a presença de organoclorados, HCB, DDT e $\mathrm{HCH}$, além de PCBs e metais pesados, em ovos de gaivotas coletados em 4 regiões. Todos os ovos coletados mostraram a presença de algum dos contaminantes. O HCB e o DDT tiveram diferenças significativas entre as regiões amostradas no período deste estudo, que foi de 1983 e 1986 . Os autores não conseguiram relacionar a diferenças no ambiente e a quantidade de praguicidas encontrados, bem como não observaram anomalias nas espécies estudadas.

Speich et al. (1992), em áreas industriais do Estado de Washington nos EUA, estudaram o efeito dos contaminantes PCBs e DDT na formação dos ovos. No material analisado, coletado de aves aquáticas do local, não foi observada nenhuma má formação na casca, bem como nos embriões dos animais que pudesse ser relacionada à poluição do local.

Horthem et al. (1995) estudaram ovos de aves aquáticas coletados em diferentes lugares na Baia de São Francisco nos EUA, no período de 1989 a 1991, e observaram que os organoclorados provocaram algumas alterações na reprodução dos animais, porém as concentrações encontradas eram baixas para associar este distúrbio à presença dos contaminantes.

Heinz et al. (1995), no período de 1977 a 1990 analisaram ovos de patos selvagens da região do lago Michigan nos EUA, para os organoclorados DDT, dieldrim, canfecloro, mirex, endrim, clordano, PCBs, DDE heptacloro epóxi, HCB oxiclordano e nanocloro. Os autores observaram uma diminuição na concentração dos praguicidas organoclorados, tais como, o pp'DDE que teve um decréscimo de 
$66 \%$ do período de $1977-78$ a 1990 , e do dieldrim de $16 \%$. Neste trabalho também foi verificada a taxa de eclosão dos ovos das aves, observando um aumento no período de $79,1 \%$ para $83,5 \%$. A diminuição na contaminação do ambiente pode ter favorecido o aumento na taxa de eclosão dos ovos.

Pastor et al. (1996), na Espanha, estudaram a distribuição dos contaminantes organoclorados e PCBs em gemas de ovos de aves e embriões de aves. Durante o período estudado, 1993, os autores observaram que os principais contaminantes de aves são o DDT e os PCBs. A avaliação da gema e dos embriões mostrou que as gemas são mais contaminadas do que os embriões e o conteúdo do saco aminiótico das aves.

Burger, et al. (1995), nos EUA, estudaram aves marinhas e observaram a textura da casca dos ovos das aves; este parâmetro muito utilizado desde os anos 1960 para avaliar a contaminação do meio ambiente, principalmente por praguicidas organoclorados. Os ovos coletados e analisados no início dos anos 1970, 1980 e 1990 mostraram aumento na espessura da casca. Os autores associaram este fator à diminuição dos níveis de poluentes, principalmente os praguicidas organoclorados.

Custer et al. (2000), nos EUA, observaram a presença de organoclorados e PCBs em ovos de diferentes espécies de aves, na região do rio Mississipi, no Estado de lowa. Neste estudo, os autores citam que as andorinhas são muito utilizadas como bioindicadores. O mirex foi encontrado em apenas um ovo dos ninhos analisados, enquanto o pp'DDD em 4 ovos e o pp'DDT em um ovo; todos em concentrações inferiores a 0,05 $\mu \mathrm{g} / \mathrm{g}$. O pp'DDE esteve em torno de 0,11 a 0,17 $\mu \mathrm{g} / \mathrm{g}$; dieldrin, 0,03 $\mu \mathrm{g} / \mathrm{g}$; oxiclordano, 0,02 a 0,04 $\mu \mathrm{g} / \mathrm{g}$; heptacloro epóxido 0,05 a $0,07 \mu \mathrm{g} / \mathrm{g}$ e transnanocloro 0,01 a $0,03 \mu \mathrm{g} / \mathrm{g}$. Apesar dos resultados obtidos, os 
praguicidas organoclorados não foram detectados nos alimentos consumidos pelas aves, tais como, animais bentônicos.

Henny, et al. (1998), na Rússia, coletaram 52 amostras de ovos de 12 diferentes espécies de aves de rapina; o estudo ocorreu durante o período de 1992 a 1993. Apesar da contaminação por praguicidas organoclorados ter sido freqüente, a concentração encontrada estava abaixo daquela a qual efeitos deletérios podem ser associados.

Bowerman et al. (1998) analisaram ovos de águias, no Canadá, os autores avaliaram o uso de águias como bioindicadores da qualidade da água e aspectos reprodutivos em relação à presença de contaminantes, tais como, PCBs e praguicidas organoclorados. Não foi observada mudança na concentração dos contaminantes estudados e os autores sugerem que estes resultados estão relacionados à migração destes animais.

Pekarik et al. (1998), no Canadá, comentaram sobre a análise de ovos de gaivota, coletados em 13 colônias, durante o período de 1974 a 1885 . Os autores avaliaram a presença de organoclorados e através de tabulações estatísticas dos dados, foi observada uma flutuação nos níveis de contaminação durante o período estudado; alguns praguicidas, como o dieldrim e o heptacloro epóxido, mostraram uma maior diminuição dos níveis de contaminação.

Berny et al., na França, em 2002, observaram a contaminação do ambiente por indústrias e áreas agrícolas, quanto ao desenvolvimento das aves (garças) da região, no período de 1996. Dentre os níveis encontrados de organoclorados, o lindano foi aquele que apresentou maior concentração: 0,01 a $0,7 \mu \mathrm{g} / \mathrm{g}$; esta quantidade, porém não esteve associada a distúrbios no desenvolvimento das aves. Quanto ao DDE, foi encontrado até $1,0 \mu \mathrm{g} / \mathrm{g}$. 
No estudo de Elliott et al. (1998), no Canadá, foram coletados ovos e plasma de águias em diferentes regiões no Estreito de Geórgia, para avaliar a presença de praguicidas organoclorados. Os autores não observaram diferença entre as regiões para os praguicidas organoclorados, tais como o DDE. A presença de contaminantes nas regiões estudadas não levou os autores a concluir que os contaminantes interferiram na reprodução dos animais.

Clark et al. (2001) relatam que aves aquáticas são bons bioindicadores de estuários marinhos, principalmente devido à dieta alimentar exclusiva, composta de peixes. Em estudo realizado na costa do Atlântico e rio Maurício em Nova Jersey, EUA, os autores avaliaram aves aquáticas e observaram a presença de DDT em níveis elevados; alguns outros contaminantes contribuíram para uma diminuição na reprodução destes animais. O estudo conduzido no período de 1989 foi repetido em 1998 e os autores constataram que redução de muito dos contaminantes, tais como, o DDE de 1,2 a 3,2 mg/kg para 0,7 a 1,2 mg/kg. Ao avaliar o alimento destas aves observou-se também uma diminuição na contaminação, sendo para o DDE de 0,05 a $0,69 \mathrm{mg} / \mathrm{kg}$ para 0,03 a $0,13 \mathrm{mg} / \mathrm{kg}$. Os autores justificam que estes estudos de monitorização são importantes para controlar a presença de contaminantes no meio ambiente.

Weber et al. (1998), na Alemanha, coletaram 60 ovos de aves de rapina e pesquisaram organoclorados. $\mathrm{O}$ pp'DDE esteve presente nos ovos em baixa concentração. Os ovos da área industrial tinham mais $\mathrm{HCB}$ e beta $\mathrm{HCH}$ do que aqueles da área rural, enquanto o pp'DDT foi encontrado na área rural. Durante o estudo, de 1987 a 1993, observou-se uma diferença na distribuição dos contaminantes, como, por exemplo, $\mathrm{HCB}$, beta e gama $\mathrm{HCH}$ diminuíram entre 1990 e 1991. 
Nagel et al. (2001) estudaram ovos de pomba, na Suíça como bioindicadores de contaminação do ambiente. Esses autores observaram que entre os organoclorados, o DDE era o único presente nas amostras de ovos analisadas. Comparando com os ovos de pombas de outras localidades, os autores julgaram que os níveis encontrados para os organoclorados e outros poluentes orgânicos apresentaram níveis baixos de contaminação. No estudo ficou destacada a importância de se utilizar ovos de pombas como bioindicadores dos níveis de poluição e a contribuição do risco a saúde, destes poluentes em áreas urbanas.

Weselch et al. (1994), na região dos Grandes Lagos no Canadá, em estudo feito em 1983, verificaram que muitos ovos apresentaram-se contaminados por praguicidas organoclorados, como o pp'DDE, o dieldrim, o heptacloro epoxido, o HCB e o dodecacloro, sendo observado um declínio no nível de contaminantes organoclorados de $84 \%$ desde 1974 . Os autores não estabeleceram relação entre a distribuição dos contaminantes na dieta alimentar e as cascas dos ovos se mostraram $8 \%$ mais finas do que o estudo anterior, e estas não foram a causa do não desenvolvimento dos embriões. Os autores associaram a diminuição do desenvolvimento com aspectos como desaparecimento dos ovos e o canibalismo. A redução do principal alimento na região foi a causa da diminuição das colônias.

Ryckman et al. (1998), na região dos Grandes Lagos no Canadá, estudaram ovos de cormorão, no período de 1970 a 1995. O estudo de monitorização, quanto a contaminação dos ovos por praguicidas organoclorados, mostrou que o pp'DDE esteve presente em alta concentração nas amostras. Os autores observaram que a presença destes contaminantes nos diferentes pontos de coleta do lago foi desigual. Observou-se também que houve um declínio nos níveis de organoclorados e que para o DDT os níveis eram diferentes nas diferentes áreas. 
Blus et al. (1998) observaram os níveis de contaminação por praguicidas organoclorados. Foram analisados ovos de andorinha do mar e alterações no desenvolvimento dos embriões também foram constatadas. Os autores descreveram que no rio Columbia (América do Norte) na região de Wallula há uma indústria produtora de papel e o cloro ou substâncias cloradas utilizadas no branqueamento do papel contaminam a região, principalmente com dioxinas e furanos. Muitos dos peixes coletados na região apresentaram elevados índices dessas substâncias. Os autores, porém, relataram que às anormalidades dos embriões não podem ser relacionadas aos $\mathrm{PCBs}$ e organoclorados presentes nos ovos das aves e a presença da fábrica de papel.

Albanis et al. (1995) avaliaram ovos de pelicano, bem como seu principal alimento, as enguias. As amostras foram coletadas no período de 1992 e 1993, na Grécia, e apresentaram contaminação por Alfa $\mathrm{HCH}$ 7,9 $\mu \mathrm{g} / \mathrm{g}$; beta $\mathrm{HCH} 16,42 \mu \mathrm{g} / \mathrm{g}$; lindano 7,65 $\mu \mathrm{g} / \mathrm{g}$; pp'DDD 4,28 $\mu \mathrm{g} / \mathrm{g}$; pp'DDE 5,42 $\mu \mathrm{g} / \mathrm{g}$; e pp'DDT 4,4 $\mu \mathrm{g} / \mathrm{g}$. Os autores relataram que no período de 1950 a 1960 houve o uso de praguicidas organoclorados em larga escala e que estes compostos foram banidos em 1972. Os estudos mostraram a presença desses compostos na alimentação das aves (enguias) e também no sedimento e água.

Heinz et al. (1994), no período de 1977 a 1990 estudaram a presença de PCBs e praguicidas organoclorados, tais como, DDT, dieldrim, canfecloro, mirex, endrim, HCB, oxiclordano e nonacloro em ovos de aves aquáticas presentes no lago Michigan no Estado de Wisconsin, nos EUA. Os autores observaram que houve uma diminuição a presença destes contaminantes, sendo que os PCBs descresceram em $60 \%$, o pp'DDE em $66 \%(6,5 \mathrm{mg} / \mathrm{kg}$ para $2,2 \mathrm{mg} / \mathrm{kg})$ e o dieldrim decresceu $16 \%$ $(0,82 \mathrm{mg} / \mathrm{kg}$ para $0,69 \mathrm{mg} / \mathrm{kg})$. 
Scharenberg et al. (1998) ressaltaram a importância da análise de ovos de aves migratórias como um recurso para se observar a contaminação-bioindicador. O locar escolhido foi o lago Belau situado ao norte da Alemanha e que é bem conhecido por ter baixos níveis de contaminação. A coleta ocorreu no período de 1993 a 1995 e utilizaram o método S19 e extração com soxlet. Foi encontrado HCB (0,02 $\mathrm{mg} / \mathrm{kg})$, beta $\mathrm{HCH}(0,003 \mathrm{mg} / \mathrm{kg})$, gama $\mathrm{HCH}(0,004 \mathrm{mg} / \mathrm{kg})$, pp'DDE $(1,55$ $\mathrm{mg} / \mathrm{kg})$ em mergulhão; e para gaivota pp'DDE $(0,06 \mathrm{mg} / \mathrm{kg})_{\overline{\bar{\zeta}}} \mathrm{pp}{ }^{\prime} \mathrm{DDT}(0,009 \mathrm{mg} / \mathrm{kg})$ e pp'DDD (0,003 mg/kg). Os ovos foram coletados em 5 áreas e os ovos de mergulhão foram os que apresentaram as maiores concentrações para o DDT, o BHC e HCB; as diferenças encontradas estão relacionadas a dieta alimentar e ao metabolismo das aves.

Goutner, et al. (2001), em coleta de ovos de aves marinha feitas no mar Egeu, na Grécia, em estudo feito no período de 1997 a 1998, observaram a presença de praguicidas organoclorados e atribuíram as diferenças ocorridas na variedade e concentração dos contaminantes à dieta alimentar. Os autores observaram em 1997 a presença de heptacloro e DDD nos ovos das aves e, em 1998, o heptacloro epóxido; um fator importante na distribuição dos praguicidas foi relacionado à poluição do ambiente marinho. A presença dos contaminantes não provocou efeitos adversos à reprodução dos animais.

Considerando os trabalhos acima citados, nos quais se estudou aves de vida livre e a contaminação do meio ambiente, ficou evidente que os praguicidas organoclorados são aqueles mais encontrados nas amostras coletadas, devido sua grande estabilidade química e persistência no meio ambiente. 


\subsection{RISCO ASSOCIADO À PRESENÇA DE PRAGUICIDAS NOS ALIMENTOS}

A avaliação dos níveis de resíduos de praguicidas nos alimentos deve ser muito estudada, não só em produtos de origem animal, como também naqueles de origem vegetal. Estes estudos de monitorização servem como indicadores da qualidade dos alimentos e ornecem dados para se estabelecer o risco à saúde humana e de outros seres vivos associada à presença destas substâncias nos alimentos. Devido às características físico-químicas dos praguicidas, estes podem permanecer nos alimentos e o risco a saúde deve ser considerado.

Muitos dos praguicidas comercializados no mundo apresentam LMR estabelecidos tanto para produtos de origem animal, como o ovo de galinha, como também para produtos de origem vegetal, como o milho, citado anteriormente. No Brasil, apenas 4 praguicidas possuem LMR estabelecido para ovo. É importante salientar que a dieta alimentar é composta de diversos alimentos e assim a probabilidade de estar exposto aos praguicidas por diferentes fontes é grande, além da possibilidade de um praguicida estar presente em mais de um tipo de alimento. Pode-se citar, como exemplo, aqueles que apresentam LMR em ovo, como, a ciromazina, o 2,4-D, o carbaril, a etiona e o tidiazurom. Estes praguicidas apresentam LMR em outros alimentos importantes da dieta alimentar humana, como o arroz, a banana, a batata, a cebola, o feijão, a maçã, a laranja, o pepino, o tomate etc. Desta forma, a somatória da presença destes produtos nos diferentes alimentos, associada à de outros praguicidas provoca uma maior exposição ao risco para estas substâncias químicas. Para esses praguicidas, a ingestão de ovo, de acordo com a dieta básica brasileira (IBGE, 2004) há uma contribuição de 5,9\% da IDA para a 
ciromazina, de $78,3 \%$ para o carbaril, $47 \%$ para a etiona, de $2,3 \%$ para o $2,4-\mathrm{D}$ e sem valor para o tidiazurom, que não possui estudo toxicológico para o estabelecimento da IDA até o presente momento.

É possível observar nos trabalhos citados anteriormente que resíduos de praguicidas são comuns de serem encontrados, podendo estar presentes nos alimentos em valores seguros. De acordo com os estudos toxicológicos existentes, os alimentos devem ser continuamente avaliados para se conhecer o risco de consumir resíduos de praguicidas.

Em particular, o praguicida alacloro detectado em uma das amostras de ovo analisada, considerando o risco à saúde do consumidor, mostrou que independente da quantidade encontrada e, apesar de não haver IDA estabelecida para este herbicida, a presença desta substância pode ser associada a risco à sua saúde. Também deve ser ressaltado que a constatação deste herbicida no alimento estudado pode estar associada à prática agrícola, uma vez que é utilizado em cultura de milho e não existe produto veterinário registrado no MAPA que contenha essa substância como princípio ativo.

Estudos toxicológicos feitos com o alacloro demonstraram que animais de laboratório (ratos e camundongos) apresentaram aumento na incidência de adenocarcinomas nasal, estomacal e pulmonar (MÍDIO; MARTINS, 1997). Ainda, de acordo com o International Programme on Chemical Safety, o alacloro pode estar relacionado a problemas no fígado e como agente cancerígeno (ICPS, 2007). Essas informações servem de subsídios para reforçar a importância do monitoramento de resíduos em alimentos, visando reduzir o risco à saúde humana. 
Finalizando, é importante destacar também que a produção de alimentos tanto para o consumo humano, como animal, e o meio ambiente devem ser mantidos o mais seguro possível para a manutenção da qualidade de vida. 
CONCLUSÕES 


\section{CONCLUSÕES}

Os estudos de recuperação mostraram que o método analítico DFG S19 para a pesquisa simultânea de vários praguicidas em amostras de ovo é bastante eficiente.

Os limites de quantificação para os praguicidas pesquisados em amostras de ovo variaram de $0,003 \mathrm{mg} / \mathrm{kg}$ a $0,060 \mathrm{mg} / \mathrm{kg}$ e estes atendem as necessidades para pesquisas de resíduos, seguindo orientação dos LMR estabelecidos pela legislação brasileira e Codex Alimentarius.

Os praguicidas organoclorados foram os que apresentaram os menores limites de quantificação, como os isômeros do DDT e $\mathrm{HCH}$, bem como alguns piretróides, como cipermetrina, fenpropatrin e fenvarelato.

Apenas o herbicida alacloro foi encontrado em uma única amostra das 150 analisadas, na quantidade de $0,01 \mathrm{mg} / \mathrm{kg}$. 
REFERÊNCIAS 


\section{REFERÊNCIAS}

ALBERT, L. A.; RENDON-VON-OSTEN, J. Contamination por compuestos organoclorados en algunos alimentos procedentes de una region de Mexico. Revista de Saúde Pública, v. 22, n. 6, p. 500-506, 1988.

ALBANIS, T. A.; HELA, D. G.; HATZILAKOS, D. Organochlorine residues in eggs of Pelicanus crispus and its prey in wetlands of Anvrakikos Gulf, north-western Greece. Chemosphere, v. 31, n. 11/12, p. 4341-4349, 1995.

ANASTASIADES, M.; LEHOTAY, S. Fast and easy multiresidue method employing acetonitrile extraction/partitioning and "Dispersive soilid-phase extraction" for the determination of pesticide residues in produce. Journal of Association of Official Analytical Chemists - International, v. 86, n. 2, p. 412-431, 2003.

ARGOTE-RIVERO, T.; ARIAS-VERDES, J. A.; IZQUIERDO-PEREZ, L.; FERNÁNDEZ-GARCIA, A. Niveles de plaguicidas organoclorados en huevos, en ciudad de la Habana, 1984. Revista Cubana de Higiene y Epidemiologia, v. 26, n.1, p. 27-31, 1988.

BARRRET, A. R.; SKAARE, J. U.; GABRIELSEN, G. W. Recent changes in levels of persistent organochlorines and mercury in eggs of seabirds from the Barrents sea. Environmental Pollution, v. 92, n. 1, p. 13-18, 1996.

BARRETO, H. H. C.; INOMATA, O. N. K.; LEMES, V. R. R. Níveis de pesticidas organoclorados em gordura de frango, 1988-1991. Revista do Instituto Adolfo Lutz, v. 52, n. 1/2, p. 97-1000, 1992.

BENEZ, S. M. Carnes das aves de caça e ovos: cuidados para o consumo. Revista Higiene Alimentar, v. 11, n. 52, p. 06-14, 1997.

BENNETT, R. S.; WILLIANS, B. A.; SCHMEDDING, D. W.; BENNETT, J. K. Effects of dietary exposure to methyl parathion on egg laying and incubation in mallards.

Environment Toxicology and Chemistry, v. 10, n. 4, p. 501-507, 1991.

BERNY, P.; SADOUL, N.; DOL, S.; VIDEMAN, B.; KAYSER, Y.; HAFNER, H. Impact of local agricultural and industrial practices on organic contamination of little egret (Egretto garzetta) eggs in the Rhone Delta. Southern France. Envrionment Toxicology and Chemistry, v. 21, n. 3, p. 520-526, 2002.

BERTECHINI, A. G. Nutrição: mitos e verdades sobre o ovo de consumo. Avisite, 2003. Trabalho publicado nos Anais da Conferência APINCO 2003, pág. 19. (Disponível em: <http://www.avisite.com.br/cet/trabalhos.asp?codigo=64 > . Acesso em: 09 out. 2008. 
BINATO, G.; ANGELETTI, R.; PIRO, R.; Del - Re - AAM; CAPRI, E.; EVANS, S. P.; NATALI, P.; TREVISAN, M. Pesticide contamination in animal tissues and foods, monitoring results 1993-1994-1995. In: SYMPOSIUM PESTICIDE CHEMISTRY, 10., 1996, Castelnuovo Fogliani, Italia. Proceedings... 1996, p.473-481.

BLUS, L. J.; MELANCON, M. J.; HOFFMAN, R. J.; HENNY, C. J. Contaminants in eggs of colonial waterbirds and hepatic cytochrome P450 enzyme levels in Pipped Tern Embryos, Washington State. Archives of Environmental Contaminants and Toxicology, v. 35, n. 3, p. 492-497, 1998.

BOWERMAN, W. W.; BEST, D. A.; GRUBB. T. G.; ZIMMERMAN, G. M.; GIESY, J. P.; GILBERSON, M.; FOX, G. A. (Ed.). Trends of contaminants and effects in bald eagles of the great lakes Basin. Trends in levels and effects of persistent toxic substances in the Great Lakes. Environmental Monitoring and Assessment, v. 53, n. 1, p. 197-212, 1996. Trabalho apresentado no Workshop on Environmental Results, 1998, Windsor, Ontario, Canada.

BRASIL. Ministério da Agricultura. Pecuária e Abastecimento. Decreto n 56.585 de 20/07/65. "Especificação para a classificação e fiscalização do ovo". 1965.

Disponível em: <http://extranet.agricultura.gov.br/sislegisconsulta/consultarLegislacao.do?operacao=visualizar\&id=4016 >. Acesso em: 09 out. 2008.

BRASIL. Ministério da Agricultura. Pecuária e Abastecimento. CIPOA - Resolução no. 005 de 05/07/1991. 2006. Disponível em:

$<$ http://www.agricultura.gov.br/pls/portal/docs/PAGE/MAPA/PRINCIPAL/DOCUMENT OS/MANUAL \%20PARA\%20ADES\%C3O\%20\%20SISBI\%20POA\%20\%20VERS\%C30\%20PARA\%20DIVULGA\%C7\%C3O\%20NO\%20SITE.DOC>. Acesso em: 09 out. 2008.

BRASIL. Ministério da Agricultura. Pecuária e Abastecimento. Pecuária, rebanho, abate, produção de carnes e leite, importação e exportação - Brasil - Agricultura Brasileira em números. Anuário 2004. 2004. Disponível em:

<http://www.agricultura.gov.br/spa>. Acesso em: 09 out. 2008.

BURGER, J.; VISCIDO, K.; GOCHFELD, M. Eggshell thickness in marine birds in the New York bight, 1970s to 1990s. Archives of Environmental Contaminants and Toxicology, v. 29, n. 2, p. 187-191, 1995.

CARBONE, G. T.; SATO, G. S.; MOORI, R. G. Logística reversa para embalagens de agrotóxicos no Brasil: Uma visão sobre conceitos e práticas operacionais. In: CONGRESSO DA SOBER, 43., 2005,Ribeirão Preto. Anais... Ribeirão Preto: Sociedade Brasileira de Economia e Sociologia Rural, 2005, p. 1-15.

CASARETT, L.; KLAASSEN, C. D.; AMDUR, M. O. DOULL, J. Toxicology -the basic science of poisons. 6th ed. Nova York: Macmillan Publishing company, 1996, p. 1111. 
CLARK, K. E.; STANLEY, W.; NILES, L. J. Changes in contaminant levels in New Jersey osprey eggs and prey, 1989 to 1998. Archives of Environmental

Contaminants and Toxicology, v. 40, n. 2, p. 277-284, 2001.

FAO/WHO. Food Standards. Codex Alimentarius. Definitions for the purposes of the Codex Alimentarius. 2. ed. Roma: FAO/WHO, 1993, v. 1, p. 11-13.

FAO/WHO. Food Standards. Codex Alimentarius. Raport de la trente et unième session du comite du codex sur les residues de pesticides. 1999. Disponível em: <http://www.codexalimentarius.net/web/standard list.do?lang=en>. Acesso em: 31 out. 2008.

FAO/WHO. Food Standards. Codex Alimentarius. Codex maximum residue limits; extraneous maximum residue limits. 2008. Disponível em:

$<$ http://www.codexalimentarius.net/mrls/pestdes/jsp/pest_q-e.jsp>. Acesso em: 13 out. 2008.

FAO/WHO. Food Standards. Codex Alimentarius. Raport of Joint AOAC/FAO/IAEA/IUPAC International Workshop on Practices of Method Validation. 1999. Disponível em:

<http://www.codexalimentarius.net/web/standard list.do?lang=en>. Acesso em: 31 out. 2008.

FAO/WHO. Food Standards. Codex Alimentarius. CX/RVDF 0119 - Codex committee on residues of veterinary drugs in food. Discussion paper on risk analysis. Principles and methodologies in the codex committee on residues of veterinary drugs in foods. 2001. Disponível em:

$<$ http://www.codexalimentarius.net/web/standard list.do?lang=en>. Acesso em: 31 out. 2008.

FAO/WHO. Food Standards. Codex Alimentarius. Programme mixte, FAO/OMS sur les norme alimentaires. Rapport de la vingt-troisième session du Comitè du codex sur les Methòdes d'analyse et d'echantillonnage. 2001. Sec. 24.

Disponível em: <http://www.codexalimentarius.net/web/standard list.do?lang=en>. Acesso em: 31 out. 2008.

COMPÊNDIO DE PRODUTOS VETERINÁRIOS - SINDAN. 2008. Disponível em: $<$ http://www.cpvs.com.br/cpvs/index.htm>. Acesso em: 28 ago. 2008.

CUSTER, C. M.; CUSTER, T. W.; COFFEY, M. Organochlorine chemicals in the swallows nesting in pool 15 of the upper Mississipi River. Bulletin of Environmental Contamination and Toxicology, v. 64, n. 3, p. 341-346, 2000.

DARMEROUD, P. O.; ATUMA, S.; AUNE, M.; BJERSEILUS, R.; GLYNN, A.; PETERSSON GRAWE,K.; BECKER, W. Dietary intake estimations of organohalogen contaminants (dioxins, PCB, PBDE and chlorinated pesticides,e.g. DDT) base don Swedish market basket data. Food and Chemical Toxicology, v. 14, n. 9, p. 15971606, 2005. 
DIERKSMEIER, G. Resíduos, efectos y presencia em la médio. Ciudad de La Habana, Ed. Científico técnica, 2001.

DIETRICH, S.; BUTHE, A.; DENKER, E.; HOTKER, H. Organochlorines in eggs and food organisms of avocets (Recuervinostra avosetta). Bulletin of Environmental Contaminants and Toxicology, v. 58, p. 219-226, 1997.

DONOGHUE, D. J.; HARRISSON, H.; GAINES, S.; BARTHOLOMEW, M. J.; DONOGHUE, A. M. Modeling residue up take in eggs. 1. Similar drug residue patterns in developing yolks following injection with ampicillin or okytetracycline. Poultry Science, v. 75, p. 321-328, 1995.

DONOGHUE, D. J.; HAIRSTON, H.; HENDERSON, M.; McDONALD, M.; GALINES, S.; DONOGHUE, A. M. Modeling residues up take in eggs: yolks contain ampicillin residues even after drug withdraw and non-detectabillity in plasma. Poultry Science, v. 76, p. 458-462, 1996.

DONOGHUE, D. J.; SCHENCK, F. J.; HAIRSTON, H.; PODHERNIAK, I. V.; Modeling drug residue up take in eggs: evidence of a consistent daily pattern of contamination transfer into developing pre-ovulatory yolks. Journal of Food Protection, v. 60, p. 1211-1255, 1997.

EGGS \& NUTRITION. Nutritional values of the egg. [2002]. Disponível em: $<$ http://www.nutritionandeggs.co.uk/eggs nutrition/nutrition1.html>. Acesso em: 09 out. 2008.

EL AHRAF, A.; MARZOUK, M.; WILLIS, W. V.; SALEH, R. Dieldrin in the food chain: Potential health effects of recycled animal manure. Journal of Environmental Health, v. 53, n. 1, p. 17-19, 1990.

EL-HOSHI, S. M.; NAZEM, A. M. Some chemical contaminants of public health hazard in dried egg. Assiut Veterinary Medical Journal, v. 42, n. 84, p. 24-35, 2000.

ELLIOTT, J. E.; MARTIN, P. A. Chlorinated hydrocarbons and shell thinning in eggs of (Accipiter) hawks in Ontario, 1986-1989. Environmental Pollution, v. 86, n. 2, p. 189-200, 1994.

ELLIOTT, J. E.; NORSTOOM, R. J. Chlorinated hydrocarbons contaminants and productivity of bald eagle populations on the pacific coast of Canada. Environmental Toxicology and Chemistry, v. 17, n. 6, p. 1142-1153, 1998.

FAO. FOOD AGRICULTURE ORGANIZATION. Major food and agricultural commodities and producers. [1999-2001] Disponível em:

$<$ http://www.fao.org/es/ess/top/commodity.jsp?lang=EN\&commodity=1062\&Commod ityLis>. Acesso em: 25 jul. 2007. 
FIDDLER, W.; PENSABENE, J. W.; GATES, R. A.; DONOGHUE, D. J. Supercritical fluid extraction of organochlorine pesticides in eggs. Journal of Agricultural and Food Chemistry, v. 47, p. 206-211, 1999.

FRANK, R.; BRAUN, H. E.; STONEFIELD, K. I.; RASPER, J.; LUYKEN, H. Organochlorine and organophosphorus residues in the fat of domestic farm animal species, Ontario, Canada, 1986-1988. Food Additives and Contaminants, v. 7, n. 5, p. 629-636, 1990.

FURUSAWA, N.; OKASAKI, K.; IRIGUCHI, S.; YANAGUCHI, H.; SAITOH, M. Gel permeation and florisil chromatographic clean-up and gas chromatographic determination of organochlorine pesticide in eggs. Journal of Association of Official Analytical Chemists - International, v. 81, n. 5, p. 1033-1036, 1998.

GOUTNER, V.; ALBANIS, T.; KONSTANTINOU, I.; PAPAKONSTANTINOU, K. $\mathrm{PCBs}$ and organochlorine pesticide residues in eggs of Audouin's gull (larus audouini) in the north-eastern Mediterranean. Marine Pollution Bulletin, v. 42, n. 5, p. $377-388,2001$

GEMS/FOOD. GLOBAL ENVIRONMENT MONITORING SYSTEM. FOOD CONTAMINATION MONITORING AND ASSESSMENT PROGRAMME. Guidelines for predicting dietary intake of pesticide residues (revised). Suíça: WHO, 1997.

FAO/WHO. Food and Agriculture Organization of the United Nations World Health Organization. Guide codex Recommendations concerning pesticide Residues. Rome: FAO/ WHO, 1984, Pt. 5. Recommended method of sampling for the determination of Pesticide Residues. Codex alimentarius comission.

HAYES, R. J.; CAMPBELL, T. C. Food additives and contaminants. In: CASSARET, L.; DOULL'S, J. Toxicology. The basic science of poisons. $3^{\text {rd }}$ ed. New York: 1986. Chap. 24, p. 771-800.

HENNY, C. J.; GALUSHIN, V. M.; DUDIN, P. I.; KHRUSTOV, A. V.; MISCHENKO, A. L.; MOSEIKIN, V. N.; SARYCHEV, V. S.; TURCHIN, V. G. Organochlorine pesticides, PCBs and mercury in hawk, falcon, eagle and owl eggs from the Lipetsk, Voronezh, Nougorod and Saratov Regions, Russia, 1992-1993. Journal of Raptor Research, v. 32, n. 2, p. 143-150, 1998.

HEINZ, G. H., MILLER, D. S.; EBERT, B. J.; STROMBORG, K. L. Declines in organochlorines in eggs of red breasted mergasers from Lake Michigan, 1977-1978 versus 1990. Environmental Monitoring Assessment, v. 33, n. 3, p. 175-182, 1994.

HILL, K. R. Recommended methods for the determination of residues of pyrethrins and piperonyl butoxide. Pyrethrum-Post, v. 17, n. 4, p. 133-139, 1990. 
HORTHEM, R. L.; ROSTER, D. L.; KING, K. A.; KELDSEN, T. J. MARDIS, K. C. Spatial and temporal trends of contaminants in eggs of wading birds from San Francisco Bay, California. Environmental Toxicology and Chemistry, v. 14, n. 8, p. 1319-1331, 1995.

HOWE, F. P.; KNIGHT, R. L.; McEWEN, L. C.; GEORGE, T. L. Direct and indirect effects of insecticide applications on growth and survival of nesthing passerines. Ecological Application, v. 6, n. 4, p. 1314-1324, 1996.

HUTSON, D. H.; ROBERTS, T. R. Insecticides. New York, John Willey \& Sons, 1985. v. 5, p. 385.

IBGE. INSTITUTO BRASILEIRO DE GEOGRAFIA E ESTATÍSTICA. Banco de dados agregados. Sistema IBGE de recuperação automática, Produção de ovos. 2007. Disponível em:

$<$ http://www.sidra.ibge.gov.br/bda/default.asp?t=4\&z=t\&o=1\&u1=1\&u2=1\&u3=1\&u4= $1 \& u 5=1 \& u 6=1 \& u 7=1 \& u 8=1 \& u 9=1 \& u 10=3 \& u 11=1 \& u 12=26674 \& u 13=1 \& u 14=1$ acess oㄱ. Acesso em: 13 out. 2008.

IBGE. INSTITUTO BRASILEIRO de GEOGRAFIA e ESTATÍSTICA. Pesquisa de orçamentos familiares 2002-2003 - aquisição alimentar domiciliar per capita Brasil e grandes regiões. Rio de Janeiro: IBGE, 2004.

ICPS. INTERNATIONAL PROGRAMME ON CHEMICAL SAFETY. Prepared in the context of cooperation between the International programme on chemical Safety and the European Commission - ICPS 2006. Alachlor. 1999. Disponível em:

$<$ http://www.ilo.org/public/english/protection/safework/cis/products/icsc/dtasht/ icsc0 3/icsc.0371.pdf>. Acesso em: jul. 2007.

INDRANINGSIH, M. R.; MILTON, R.; MARSHALL, R. B. Organochlorine pesticide residues in bird eggs. Penyakit Hewan. v. 20, n. 36, p. 98-100, 1988.

IUPAC. INTERNATIONAL UNION OF PURE APPLIED CHEMISTRY. Harmonized guidelines for single-laboratory validation of analytical methods for trace-level concentrations of organic chemicals - technical report, 1999. Joint AOAC/FAO/IAEA/IUPAC Expert consultation. Pure and Applied chemistry, v. 74, n. 5, p. 835-855, 2002.

JOINT FAO/WHO FOOD STANDARDS PROGRAMME. Recommended methods of sampling for the determination of pesticide residues for compliance with MRLs.

Codex Alimentarius Commission, 1999, v. 2, Sec. 21, p. 1-20, 1999. Appendix III.

JUHLER, R. K. Optimized method for the determination of organophosphorus pesticides in meat and fatty matrices. Journal of Chromatography A, v. 786, p. 145-153, 1997. 
JUHLER, R. K.; LAUREIDSEN, M. G.; CHRISTENSEN, M. R.; HILBERT, G. Pesticide residues in selected food commodities: results from the Danish National Pesticide Monitoring program, 1995-1996. Journal of Association of Official Analytical Chemists - International, v. 82, n. 2, p. 337-358, 1999.

KAN, C. A.; TUINSTRA, L. G. M. T. Accumulation and excretion of certain organochlorine insecticides in broiler breeds hens. Journal of Agriculture and Food Chemistry, v. 24, p. 775-778, 1976.

KAN-DO Office and Pesticides Team. Accumulated pesticide and industrial chemical findings from a ten year study of ready to eat foods. Journal of Association of Official Analytical Chemists - International, v. 78, n. 3, p. 614-631, 1995.

KANNAN, K.; TANABE, S.; IWATA, H.; TATSUKAWA, R. Butyltins in muscle and liver of fish collected from certain Asian and Oceanian Countries. Envrionmental Pollution, v. 90, n. 3, p. 279-290, 1995.

KANNAN, K.; TANABE, S.; GIESY, J. P.; TATSUKAWA, R. Organochlorine pesticides and polychlorinated biphenyls in foodstuffs from Asian and Oceanic Countries. Envrionmental Contaminants and Toxicology, v. 152, n. 1, p. 1-55, 1997.

KANUNYO, J. M.; FROSLIE, A.; MAITAI, C. K. Organochlorine pesticide residues in chicken eggs: a survey. Journal of Toxicology and Environmental Health, v. 24, n. 4 , p. 543-550, 1988.

KESSABI, M.; ABDENNEBI, E.; LARAJE, R.; LHAFI, A. Contamination of eggs, poultry liver and bovine liver and kidney by chlorinated pesticides in Morocco. Science of the Total Environment, v. 90, p. 283-287, 1990.

KLINGMAN, G. O. Weed Science. Principles and practices. New York: John Willey and Sons, 1975, p. 431.

KOLBE, W. "Crop production and weed control". Pflanzenschuts Nachrichten Bayer, v. 36, p. 205-373, 1983

KUWABARA, K.; MATSUMOTO, H.; MURAKAMI, Y.; HORI, S. Daily dietary intakes of PCBs and organochlorine pesticides during 19 years from 1977 to 1995 by adults in Osaka evaluated by the total diet study method. Journal of Food Hygienic of Society of Japan, v. 38, n. 5, p. 286-295, 1997.

LI, Y. F.; CAI, D. J.; SINGH, A. Technical hexachlorocyclohexane use trends in China and their impact in the environment. Archives of Environmental Contaminants and Toxicology, v. 35, n. 4, p. 688-697, 1998. 
LUKE, B. G.; JOHNSTONE, G. W.; WOEHLER, E. J. Organochlorine pesticide PCB's and mercury in Antartic and Subantartic seabirds. Chemosphere. v. 19, n. 12, p. 2007-2021, 1989.

THEIR, H. P.; ZEUMER, H. (Ed.). Deutsche Forschungsgemeinschaft, Pesticide Comm. Ed. By. New York: WILEY-VCH Verlag GmbH \& Co. KGaA, 1992, 2 v. (Manual Of Pesticide Residue Analysis, v. 1).

MATTOS, L. L.; MARTINS, I. S. Consumo de fibras alimentares em população adulta. Revista de Saúde Pública. Disponível em: <http://www.scielosp.org/cgibin/wxis.exe/iah/>. Acesso em: 09 out. 2008.

MÍDIO, A. F.; MARTINS, D. I. Herbicidas em alimentos: aspectos gerais, toxicológicos e analíticos, São Paulo: Editora Varela, 1997, p. 104.

MÍDIO, A. F.; MARTINS, D. I. Toxicologia dos alimentos. São Paulo: Varela, 2000.

MODULAR MULTIPLE REVISED VERSION OF THE DFG METHOD S19. Modular multiple analytical method for the determination of pesticide residues in foodstuffs. Collection of Official Methods under article 35 of the German Federal Food Act as method L00.00-34, November 1999. Disponível em:

$<$ http://www.methodensammlungbvl.de/cn/bGV2ZWw9dHBsLXN1Y2hlcmdlYm5pcyZsaW1pdGF0aW9udHIwZT0mc2V hcmNoYWNjZXNza2V5PUNPTIRFTIQmcGFnZWIkPTY*.html>. Acesso em: 09 out. 2008.

MONTEIRO, E. Esse negócio dá lucro! A hora do ovo, ano 9, v. 42, p. 12, 2005

MOURER, C. R.; HALL, G. L.; WHITEHEAD, W. E.; SHIBAMOTO, T.; SHULL, L. R.; SCHWARZBACH, S. E. Chromatographie determination of dicofol and metabolites in egg yolks. Archives of Environmental Contaminants and Toxicology, v. 79, n. 1, p. 154-156, 1990.

MUGAMBI, J. M.; KANJA, L.; MAITHO, T. E.; SKAARE, J. H.; LOKKEN, P. Organochlorine pesticide residues in domestic fowl (Gallus domesticus) eggs from central Kenya. Journal of Science Food and Agriculture, v. 48, n. 2, p. 165-176, 1989.

NAGEL, P.; SMREKAR, G.; HAAG-WACKERNAGEL, D. Use of fetal pigeon eggs for urban biomonitoring. Fresenius Environmental Bulletin, v. 10, n. 1, p. 18-25, 2001.

NIEWLADOWSKA, A.; ZMUDZKI, J.; SEMENIUK, S. Residues of organochlorine pesticides and polychlorinated biphenyls in hen eggs. Bromatologia i Chemia Toksykologiozna, v. 29, n. 1, p. 79-83, 1996 
NOBLE, A. The relation between organochlorine residues in animal feeds and residues in tissues, milk and eggs: a review. Australian Journal of Experimental Agriculture, v. 30, p. 145-54, 1990.

ORMEROD, S. J.; TYLER, S. J. Inter and intra annual variation in the occurrence of organochlorine pesticides, polychlorinated biphenyl congeners and mercury in the eggs of a river passerine. Archives of Environmental Contaminants and Toxicology, v. 26, n. 1, p. 7-12, 1994.

O'HALLORAN, J.; ORMEROD, S. J.; SMIDDY, P.; O'MAHONY, B. Organochlorine and mercury content of dipper eggs in southwest Ireland. Biology and environment: Proceedings of the Royal Academy Section B., v. 93, p. 25-31, 1993.

PALERMO NETO, J. Considerações gerais sobre o uso de agentes que alteram a produção animal. In: SPINOSA, H. S.; GÓRNIAK, S. L.; BERNARDI, M. M. Farmacologia aplicada à medicina veterinária. 4. ed. Rio de Janeiro: Guanabara Koogan, p. 587-595, 2006.

PASTOR, D.; RUIZ, X.; JOVER, L.; ALBAIGES, J. The use of chorioallantoic membranes as predictors of egg organochlorine. Environmental Toxicology and Chemistry, v. 15, n. 2, p. 167-171, 1996.

PEKARIK, C.; WESELOH, D. V.; GILBERTSON, M.; FOX, G. A.; BOHERMAN, W. W. Organochlorine contaminants in herring gull eggs from the Great Lakes, 19741995: change point regression analysis and short-term regression. Trends in levels and effects of persistent toxic substances in the Great Lakes. Environmental Monitoring Assessment, v.53, n. 1, p. 77-115, 1998. Trabalho apresentado no Workshop on Environmental Results, Windsor, Ontario, Canada, 12-13, September 1996.

PELLANTOVA, J.; HUDEC, K.; KREDL, J. Organochlorine pesticides, PCB and heavy metals residues in the eggs of the black-heated gull, Larus ridibundus in Czechoslovakia. Folia Zoologika, v. 38, n. 1, p. 79-86, 1989.

ROMÃO, G. O.; PONTES NETTO, I.; SASSAHARA, M. I.; TAJIRI, A. N. I.; FUJIKAWA, A.; ARRUDA, M. I.; RODRIGUES, M. I. Resíduos do organofosforado dimetoato e do carbamato aldicarbe em ovos produzidos na região norte do Estado do Paraná. Brazilian Journal of Toxicology, v. 20, p. 132, 2007. Suplemento, 3.

RYCKMAN, D. P.; WESELCH, D. V.; HAMR, P., FOX, G. A.; COLLINS, B.; EWINS, P. J.; NORSTOM, R. J.; GILBERTSON, M.(Ed.); FOX, G. A. (Ed.);. BOWERMAN, W. W. Spatial and temporal trends in organochlorine contamination and bill deformities in double-crested cormorants (Phalacrocorax auritus) from the Canadian Great Lakes. Environment Monitoring Assessment , v. 53, n. 1, p. 169-195, 1998.

BARBOSA, F. J. V.; NASCIMENTO, M. P. S. B.; DINIZ, F. M.; NASCIMENTO, H. T. S.; NETO, R. B. A.; LEAL, T. M. Sistema alternativo de criação de galinhas caipiras. 2007. Disponível em: 
http://sistemasdeproducao.cnptia.embrapa.br/FontesHTML/Ave/SistemaAlternativoCr iacaoGalinhaCaipira/Alimentacao.htm >. Acesso em: 13 de nov. 2008.

SANTOS FILHO, J. I.; SCHLINDWEIN, M. M. Fatores determinantes do consumo de ovos no Brasil. In: CONGRESSO DA SOBER, 2007, Londrina. Anais... Falta local de publicação: Sociedade Brasileira de Economia, Administração e Sociologia Rural, 2007, p. 1-15.

SCHENCK, F. J.; DONOGHUE, D. J. Determination of organochlorine and organophosphorus pesticide residues in eggs using a solid phase extraction cleanup. Journal of Agricultural and Food Chemistry, v. 48, p. 6412-6415, 2000.

SCHARENBERG, W.; EBELING, E. Organochlorine pesticides in eggs of two waterbirds species (Fulica atra, Podiceps cristatus) from the same habitat: reference site lake Belau - Germany. Chemosphere, v. 36, n. 2, p. 263-270, 1998.

SPEICH, S. M.; CALAMBOKIDIS, J.; SHEA, R. W.; PEARD, J.; WITTER, M.; FRY, $M$. D. Eggshell thinning and organochlorine contaminants in western Washington waterbirds. Colonial Waterbirds, v. 15, n. 1, p. 103-112, 1992.

SINGH, P. P.; CHAWLA, R. P. Insecticide residues in total diet samples in Punjab India. The Science of the Total Environment, v. 76, p. 139-146, 1988.

SZERLETICS, T. M.; SOOS, K.; VEGH, E. Determination of residues of pyrethroid and organophosphorus ectoparasiticides in food of animal origin. Acta Veterinaria. Hungarica, v. 48, n. 2, p. 139-149, 2000.

TURLE, R.; COLLINS, B. Validation of the use of pooled samples for monitoring of contaminants in wildflife. Chemosphere, v. 25, n. 4, p. 463-469, 1992.

UEBERSCHAR, K. H. Residues in eggs and poultry meat from undesirable substances in feeds-heavy metals and organochlorine compounds. Archiv fur Geflugelvunde, v. 59, n. 6, p. 342-357, 1995.

VIEIRA, E. D.; TORRES, J. P.; MALM, O. DDT Environment persistence from its use in a vector control program: a case study. Environment Res., v. 86, n. 2, p. 174-82, 2001.

WEBER, M.; FIEBER, W.; STUBBE, M. Persistent organochlorine compounds, mercury and radionuclides in eggs of red kite (Milvus Milvus) from Saxony-Anhalt (Germany). Journal of Ornitology, v. 139, n. 2, p. 141-147, 1998.

WESELCH, D. V. C.; EWINS, P. J.; STRUGER, J.; MINEAU, P.; NORSTROM, R. J. Geographical distribution of organochlorine contaminants and reproductive parameters in herring gulls on Lake Superior in 1983. Environmental Monitoring Assessment, v. 29, n. 3, p. 229-251, 1994. 
WIGFIELD, Y. Y.; SELWYN, J.; KHAN, S.; MCDOWELL, R. Comparison of supercritical fluid extraction and solvent extraction of twenty-two organochlorine pesticides from eggs. Chemosphere, v. 32, n. 5, p. 841-847, 1996.

WIKTELIUS, S.; EDWARDS, C. A. Organochlorine insecticide residues in African fauna: 1971-1995. Reviews of Environmental Contaminants and Toxicology, v. 151, p. 1-37, 1997.

WHO. FOOD SAFETY CONSULTATIONS. GEMS/FOOD. Total diet studies report. In: International Workshop on Total Diet Studies, 3., [2004], Paris, France.

Proceedings... Geneva, Switzerlan, WHO Publications, 2004, [Proceedings of the total diet studies report].

ZMUDZKI, J.; JUSZKIEWICZ, J.; NIEWLADOWSKA, A.; SZKDDA, J.; SEMENIVK, S.; GOLEBIOWSKI, A.; SZYPOSZYNSKI, K. Chemical pollution of tissues from cattle and milk and eggs in the Zigorzelic-Bogatynia district. Medycyna Weterynaryja, $v$. 48, n. 5, p. 213-15, 1992. 